\title{
THE EPIPTERYGOID OF CROCODYLIFORMS AND ITS SIGNIFICANCE FOR THE EVOLUTION OF THE ORBITOTEMPORAL REGION OF EUSUCHIANS
}

\author{
CASEY M. HOLLIDAY ${ }^{*}, 1,2$ and LAWRENCE M. WITMER ${ }^{2}$ \\ ${ }^{1}$ Department of Anatomy and Pathology, Joan C. Edwards School of Medicine, Marshall University, Huntington, WV 25704, \\ hollidayc@marshall.edu \\ ${ }^{2}$ Department of Biomedical Sciences, College of Osteopathic Medicine, Ohio University, Athens, OH 45701, witmerL@ohio.edu
}

\begin{abstract}
A broad survey of crocodyliform archosaurs and their outgroups was conducted to explore the evolutionary and morphological patterns of the orbitotemporal region, which is a highly apomorphic but poorly understood portion of the head. Data were gathered on the topological similarity and phylogenetic congruence of the epipterygoid, laterosphenoid, and temporal region as a whole, including relevant osteological correlates and such inferred soft tissues as the trigeminal nerves and jaw musculature. Despite the complete suturing of the palatocranial junction, the epipterygoid remained a consistent cranial element throughout crocodyliform evolution, only to be replaced by the topologically analogous, but developmentally neomorphic lateral bridge of the laterosphenoid during the early evolution of eusuchians. These changes led to a unique morphology of the region surrounding the exit of the trigeminal nerve. Mesoeucrocodylian taxa exhibit a diversity of epipterygoid morphologies including waisted (e.g., Araripesuchus), overlapping (e.g., Sarcosuchus), and isolated (e.g., Goniopholis, Leidyosuchus) forms. The isolated form, in which the epipterygoid is uncoupled from the pterygoid and does not to cover the cavum epiptericum laterally, represents a key transition to the extant condition of loss of the epipterygoid. Changes in the epipterygoid coincide with the migration of M. pseudotemporalis superficialis onto the laterosphenoid outside of the dorsotemporal fossa and the topological change in the intermuscular path of the maxillary nerve, both of which are apomorphies found in extant crocodylians. These data reflect a diverse and potentially homoplastic distribution of orbitotemporal morphologies among mesoeucrocodylians and indicate that the epipterygoid was only recently eliminated in crocodyliform evolution.
\end{abstract}

\section{INTRODUCTION}

Among the many apomorphic features of crocodylians, the suturing of the pterygoid and quadrate to the braincase and the formation of a bony secondary palate are unique among diapsids (Iordansky, 1964, 1973; Langston, 1973; Busbey, 1995; Witmer, 1995; Brochu, 1999). These two attributes likely resulted in the reorganization of the epipterygoid, rostral wall of the braincase, trigeminal nerves, adductor musculature, and other neighboring structures in the crocodyliform orbitotemporal region. How these changes in the orbitotemporal region occurred are unclear and may offer additional understanding of crocodyliform phylogenetic relationships and the transition to the modern crocodylian condition.

The epipterygoid plesiomorphically links the palate to the braincase (de Beer, 1937; Rieppel, 1993) and forms the lateral wall of the cavum epiptericum (an extra-cranial space lateral to the laterosphenoid, prootic, and cranial cavity) and medial wall of the adductor chamber proper (Gaupp, 1902; Hopson and Rougier, 1993; Fig. 1). The cavum epiptericum houses the trigeminal and facial nerve ganglia, the ophthalmic division of the trigeminal nerve (Gaupp, 1902), the motor branch of the mandibular nerve that innervates the $\mathrm{M}$. constrictor internus dorsalis (Iordansky, 1964; Holliday, 2006), a branch of the vena capitis lateralis, and the profundus branch of the stapedial artery (Oelrich, 1956; Figs. 1C-E).

Extant crocodylians have previously been considered to lack a cavum epiptericum (de Beer, 1937; Bellairs and Kamal, 1981;

\footnotetext{
*Corresponding author. Current address: Assistant Professor, Program in Integrative Anatomy, Dept. of Pathology and Anatomical Sciences, M318 Medical Sciences Building, University of Missouri, Columbia, MO 65212; hollidayca@health.missouri.edu
}

Gardiner, 1982), and likewise crocodylomorphs have been described as lacking epipterygoids (Gow, 2000). However, recent evidence suggests that crocodylians do possess the cavum epiptericum, albeit modified (Holliday, 2006) in that the Mm. levator and protractor pterygoideus muscles were eliminated, and the rostral trigeminal artery, a branch of the encephalic arterial system (Sedlmayr, 2002), passes through the space rather than a branch of the stapedial artery (Figs. 2B, C). Furthermore, we show here that the epipterygoid was only recently eliminated from the head skeleton in crocodyliforms, and in its place evolved the lateral bridge of the laterosphenoid (de Beer, 1937; Iordansky, 1964; Brochu, 1999; Jouve 2005), a neomorphic bony process that maintains a topologically similar positional relationship as the epipterygoid. As with the epipterygoid, the lateral bridge of the laterosphenoid is bordered medially by the contents of the cavum epiptericum and laterally by deep temporal structures, including M. pseudotemporalis superficialis, M. pseudotemporalis profundus, and the maxillary nerve (Figs. 1G, H).

The plesiomorphic reptilian (sensu Modesto and Anderson, 2004) epipterygoid and apomorphic, extant crocodylian laterosphenoid lateral bridge exemplify two purportedly non-homologous bridge-like structures that occupy markedly similar topological positions in the adductor chamber. Both structures bound the soft tissues of the cavum epiptericum and serve as attachment for M. pseudotemporalis profundus on their lateral surfaces (Oelrich, 1956; Haas, 1973; Holliday and Witmer, 2007). However, the lateral bridge is an ontogenetically-variable, ventrolaterally-descending process of the ossified pila antotica (i.e., the laterosphenoid), whereas the epipterygoid is the ossified ascending process of the palatoquadrate cartilage (de Beer, 1937; Bellairs and Kamal, 1981). In addition, whereas in other extant reptiles the maxillary nerve passes lateral to $\mathrm{Mm}$. pseudotemporalis profundus and superficialis and thus never contacts 

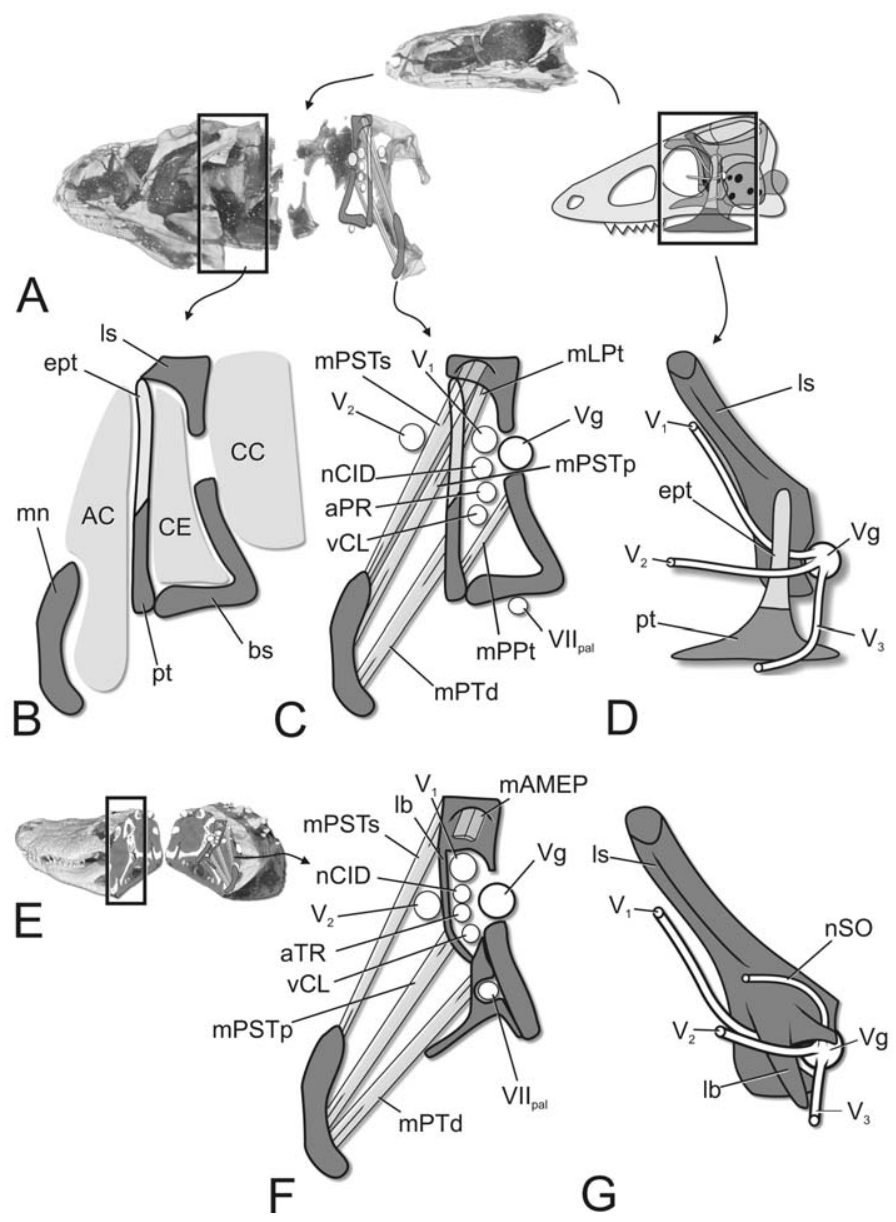

FIGURE 1. Important soft and bony structures in the orbitotemporal region of basal archosaurs and extant crocodylians. A, CT-based image of skull of the basal suchian Gracilisuchus (MCZ 4117) in left lateral view depicting location of coronal section used in B; schematic of basal archosaur in left lateral view identifying location of D. B, general cranial spaces and bones of interest in left rostral view of axial section of head through the trigeminal foramen caudal to the epipterygoid of basal archosaur; $\mathbf{C}$, relevant soft tissues (nerves, muscles, arteries), same view as B; D, schematic of palate and laterosphenoid with relevant soft tissues in left lateral view. E, CT-based image of head of Alligator in left lateral view depicting location of axial section used in $\mathrm{B} ; \mathbf{F}$, relevant soft tissues (nerves, muscles, arteries) in the extant crocodylian condition, same view as C; $\mathbf{G}$, schematic of palate and laterosphenoid with relevant soft tissues, same view as D. H, schematic of laterosphenoid and relevant soft tissues in lateral view, same view as D.

the epipterygoid (Lakjer, 1926; Holliday and Witmer, 2007), in extant crocodylians, the maxillary nerve passes medial to $\mathrm{M}$. pseudotemporalis superficialis (Holliday and Witmer, 2007) and dorsal to M. pseudotemporalis profundus where the nerve often excavates a groove on the laterosphenoid.

The mechanism by which the epipterygoid was modified, reduced, and eliminated during crocodyliform evolution is uncertain. Moreover, the evolutionary and morphological interactions between the muscles and other soft tissues of the temporal region, which includes the orbitotemporal region and dorsotemporal fossa, remain unclear. However, few researchers have focused much on the temporal region of fossil crocodyliforms (e.g., Brochu, 1999). Thus, insights from fossil taxa and the osteological correlates of informative soft tissues, coupled with extant data, may elucidate the patterns and mechanisms under-

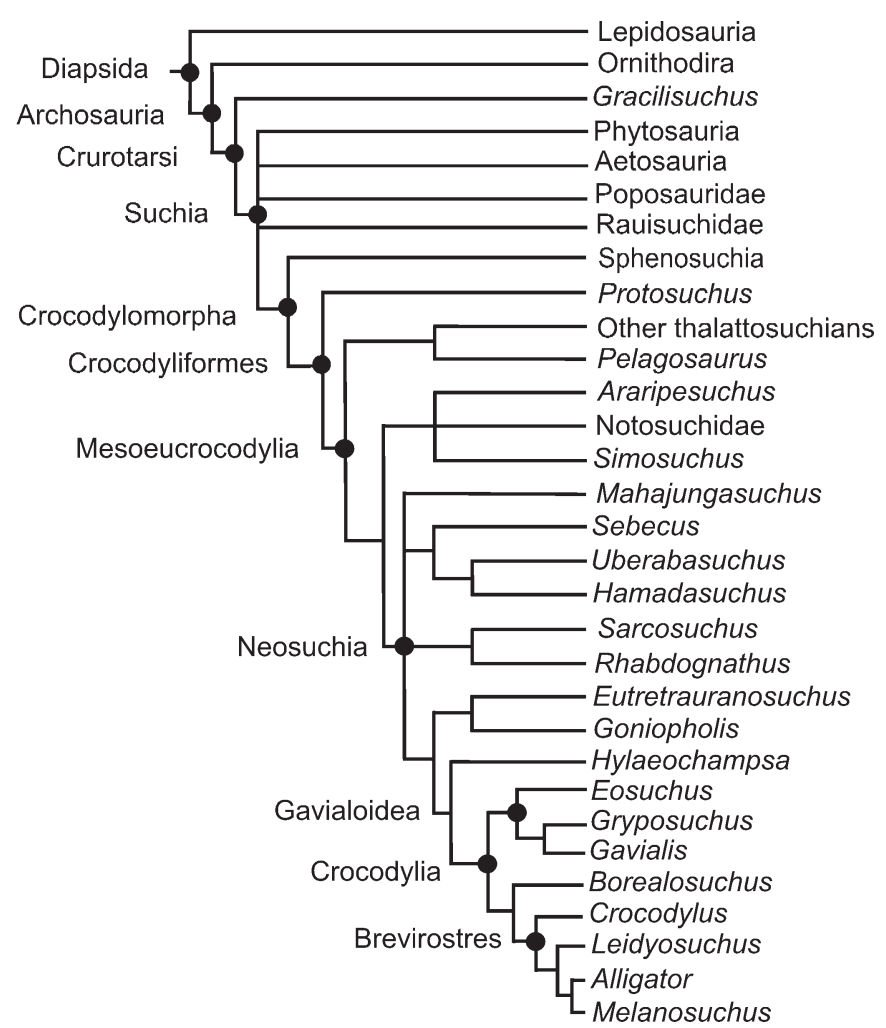

FIGURE 2. Phylogenetic framework of major clades and taxa of interest discussed in the text based on Larsson and Sues (2007).

lying the unique features exhibited by the modern crocodylian condition as well as help illuminate crocodyliform evolution. This paper discusses two suites of related morphological structures in crocodyliform evolution: the orbitotemporal region (e.g., trigeminal foramen, epipterygoid, and laterosphenoid) and the muscles of the dorsotemporal fossa.

\section{MATERIALS AND METHODS}

Data on extant crocodylians were gathered via dissection, sectioning, and imaging (computed tomography [CT], magnetic resonance imaging [MRI]; O'Bleness Memorial Hospital, Athens, Ohio) of whole Alligator mississippiensis and Crocodylus spp. specimens as part of an investigation into neuromuscular topology in the adductor chamber (Holliday and Witmer, 2007). Fossil taxa and skeletal specimens of extant crocodylians (including those dissected) from various institutions were scored for osteological correlates (e.g., grooves, tubercles, crests) of causally associated soft tissues (e.g., nerves, muscles, vessels) and other relevant osteological features (e.g., laterosphenoid morphology). These focal extant crocodylian taxa were complemented by a broad sample of fossil crocodylian, crocodyliform, basal suchian, archosauromorph, ornithodiran, and lepidosaurian taxa collected as part of a broader study of archosaur adductor chamber evolution (Holliday, 2006). Particular fossil specimens were also CT-scanned for additional data at O'Bleness Memorial Hospital (Athens, OH), Cabell Huntington Hospital (Huntington, WV) and microCT-scanned at the University of Texas High Resolution CT Laboratory (Austin, TX), Pennsylvania State University (State College, PA), and Ohio University (Athens, OH).

Numerous recent phylogenetic and biogeographical analyses have suggested that an extensive radiation of crocodyliforms occurred during the Mesozoic (e.g., Clark, 1994; Buckley et al., 
2000; Ortega et al., 2000; Sereno et al., 2001; Brochu, 2001, 2004; Sereno et al., 2003; Pol and Norell, 2004; Turner, 2004; Turner and Calvo, 2005; Jouve, 2005; Pierce and Benton, 2006; Brochu, 2007; Larsson and Sues, 2007). However, consistent phylogenetic support of relationships within and among the various clades is rare (Brochu, 2001; McAliley et al., 2006), hampering accurate analysis of character transitions. It is beyond the scope of this paper to add yet another hypothesis of crocodyliform phylogeny. Instead, representative taxa of major crocodyliform clades are analyzed in order from relatively basal (e.g., thalattosuchians) to relatively derived (e.g., eusuchians) within a phylogenetic framework largely congruent with recent analyses (Larsson and Sues, 2007; Fig. 2). Potentially informative characters and character states were mapped onto the morphological character-based phylogeny as well as a molecular data-based phylogeny to illustrate morphological patterns among the clades.

Institutional Abbreviations-AMNH, American Museum of Natural History, New York, NY; BMNH, Natural History Museum, London, UK; BRLSI, Bath Royal Literary and Scientific Institute, Bath, UK; CM, Carnegie Museum, Pittsburgh, PA; CMN, Canadian Museum of Nature, Ottawa; CMNH, Cleveland Museum of Natural History, OH; CNRST-SUNY, Centre National de la Recherche Scientifique et Technologique du MaliStony Brook University, NY; FMNH, The Field Museum, Chicago, IL; IGM, Institute of Geology, Ulaanbaatar, Mongolia; IRScNB, Institut Royal des Sciences Naturelles de Belgique, Brussels, Belgium; MCZ, Museum of Comparative Zoology, Harvard University, Cambridge, MA; MNN, Musée National du Niger, Niamey, Niger; MSM, Mesa Southwest Museum, Mesa, AZ; OUVC, Ohio University Vertebrate Collections, Athens, OH; PVSJ, Division of Vertebrate Paleontology of the Museo de Ciencias Naturales de la Universidad Nacional de San Juan, Argentina; ROM, Royal Ontario Museum, Toronto, ON; SAM, Iziko South African Museum, Cape Town; TMP, Royal Tyrrell Museum of Palaeontology, Drumheller, AB; UA, University of Antanarivo, Madagascar; UC, University of Chicago (housed at FMNH); UCMP, University of California Museum of Paleontology, Berkeley, CA; USNM, United States National Museum, Washington DC.

Anatomical Abbreviations-AC, adductor chamber; adt, adductor tubercle; $\mathbf{a P R}$, profundus artery; $\mathbf{a T C}$, caudal trigeminal artery; aTR, rostral trigeminal artery; bs, basisphenoid; cap, capitate process; CE, cavum epiptericum; cb, caudal bridge of the laterosphenoid; $\mathbf{C C}$, cranial cavity; ch, choana; cr $\mathbf{A}$, crest A; cr B, crest B; cr cot, cotylar crest; cr T, tensor crest; cup, cultriform process; dtfen, dorsotemporal fenestra; dtfo, dorsotemporal fossa; ect, ectopterygoid; ept, epipterygoid; ept cot, epipterygoid cotyle; epta, ascending process of the epipterygoid; eptb, epipterygoid body; eptc, epipterygoid caudal process; ept/ls sut, epipterygoid-laterosphenoid suture; ept/pt sut, epipterygoidpterygoid suture; f III, oculomotor foramen; f aTC, caudal trigeminal artery foramen; f MM, maxillomandibular foramen; $\mathbf{f}$ nSO, supraorbital foramen; $\mathbf{f} \mathbf{V}$, trigeminal foramen; $\mathbf{f} \mathbf{V}_{\mathbf{1}}$, ophthalmic foramen; $\mathbf{f} \mathbf{V}_{\mathbf{2 , 3}}$, maxillomandibular foramen; $\mathbf{f}$ VI, abducens foramen; $\mathbf{f}$ VII, facial nerve foramen; $\mathbf{f} \mathbf{V}_{\text {tymp }}$, tympanic foramen; f vCM, middle cerebral vein foramen; fo ept, epipterygoid fossa; fo mAMEP, mAMEP fossa; fo mPSTp, mPSTp fossa; fo mPSTs, mPSTs fossa; fo $\mathbf{V}$, trigeminal fossa; fr, frontal; g aTR, rostral trigeminal artery groove; $\mathbf{g} \mathbf{n S O}$, supraorbital nerve groove; $\mathbf{g} \mathbf{V}_{\mathbf{1}}$, ophthalmic groove; $\mathbf{g} \mathbf{V}_{\mathbf{2}}$, maxillary groove; g $\mathbf{V}_{\mathbf{2 , 3}}$, maxillomandibular ganglion; $\mathbf{g} \mathbf{V}_{\mathbf{3}}$, mandibular nerve groove; g vCL, lateral head vein groove; hc, hyaline cartilage; ju, jugal; lb, lateral bridge of the laterosphenoid; 'lb', inferred lateral bridge; Is, laterosphenoid; Isb, laterosphenoid body; mAMEM, Musculus adductor mandibulae externus medialis; mAMP, Musculus adductor mandibulae posterior; mAMEP, Musculus adductor mandibulae externus profundus; mAMES, Musculus adductor mandibulae externus superficialis; mLPt,
Musculus levator pterygoideus; mPPt, Musculus protractor pterygoideus; mPSTp, Musculus pseudotemporalis profundus; mPSTs, Musculus pseudotemporalis superficialis; mPTd, Musculus pterygoideus dorsalis; mPTv, Musculus pterygoideus ventralis; mTP, Musculus tensor periorbitae; mn, mandible; mx, maxilla; nCID, motor branch to Musculus constrictor internus dorsalis; nSO, supraorbital nerve; occ, occipital condyle; or, orbit; os, orbital surface of laterosphenoid; OT, otic region; pal, palatine; po, postorbital; pop, postorbital process of the laterosphenoid; pr, prootic; pt, pterygoid; ptb, pterygoid buttress; ptbu, pterygoid bulla; qj, quadratojugal; qu, quadrate; sq, squamosal; sut, suture; $\mathbf{V}_{\mathbf{1}}$, ophthalmic nerve; $\mathbf{V}_{\mathbf{2}}$, maxillary nerve; $\mathbf{V}_{\mathbf{3}}$, mandibular nerve; vCL, lateral head vein; vCM, middle cerebral vein; Vg, trigeminal ganglion; $\mathbf{V I I}_{\mathbf{p a l}}$, palatine ramus of facial nerve; $\mathbf{V}_{\text {tymp }}$, tympanic branch of trigeminal nerve; ?, unclear muscle attachment.

\section{RESULTS}

\section{Organization of Results}

We first present observations on the modern crocodylian condition to introduce the anatomy of the region and the derived nature of extant taxa. Results then proceed from descriptions of basal forms, including those of protosuchians, then to those of mesoeucrocodylians, neosuchians, and finally descriptions of eusuchians along the line back to the extant condition.

\section{The Extant Crocodylian Condition}

The orbitotemporal region of extant crocodylians is primarily formed by the laterosphenoid, which features a number of structures critical to interpreting the region in fossil taxa. The laterosphenoid is a roughly pyramidal element composed of: (1) a body, which forms the majority of the ventral half of the element and includes the passage for the ophthalmic nerve and rostral framework of the trigeminal fossa; (2) the postorbital process which rises dorsally from the ventral aspect of the element and is the primary site of muscle attachment; (3) the capitate process, which articulates with the postorbital and frontal bones (Iordansky, 1973) (Fig. 3); and (4) several variably extending bony processes including the lateral and caudal bridges.

The body of the laterosphenoid separates the trigeminal divisions and associated structures from more medial neural and vascular elements (e.g., abducens nerve, oculomotor nerve) and sutures to the dorsal part of the basisphenoid (Bellairs and Kamal, 1981). The laterosphenoid body also forms the rostral border of the trigeminal foramen, which is the passage for the trigeminal nerves that pass from the adductor chamber to the trigeminal ganglion and then into the midbrain. The trigeminal ganglion is quite large in extant crocodilians and excavates the large, hemispherical trigeminal fossa on the lateral surfaces of the laterosphenoid and prootic (Figs. 3, 4). The ophthalmic, maxillary, and mandibular divisions subsequently diverge from the ganglion-the first passing through the cavum epiptericum and ophthalmic foramen covered laterally by the lateral bridge and the latter two passing through the maxillomandibular foramen, which is formed by contributions of the lateral bridge, prootic, quadrate, and pterygoid, caudal to the laterosphenoid (Figs. 1, 3, 4). The supraorbital nerve, the first branch of the maxillary nerve, passes rostrodorsally from the ganglion, often through its own foramen, passes between M. pseudotemporalis superficialis and M. adductor mandibulae externus profundus, and ramifies across the caudal part of the orbit (Holliday and Witmer, 2007). The small tympanic branch of the trigeminal nerve (Killian, 1890; nerve " $x$ " of Hopson, 1979) passes caudodorsally from the ganglion through a foramen in the prootic, through a groove within the quadrate/prootic suture, and into the otic region (Fig. 4A; see Witmer et al., 2008). The latero- 


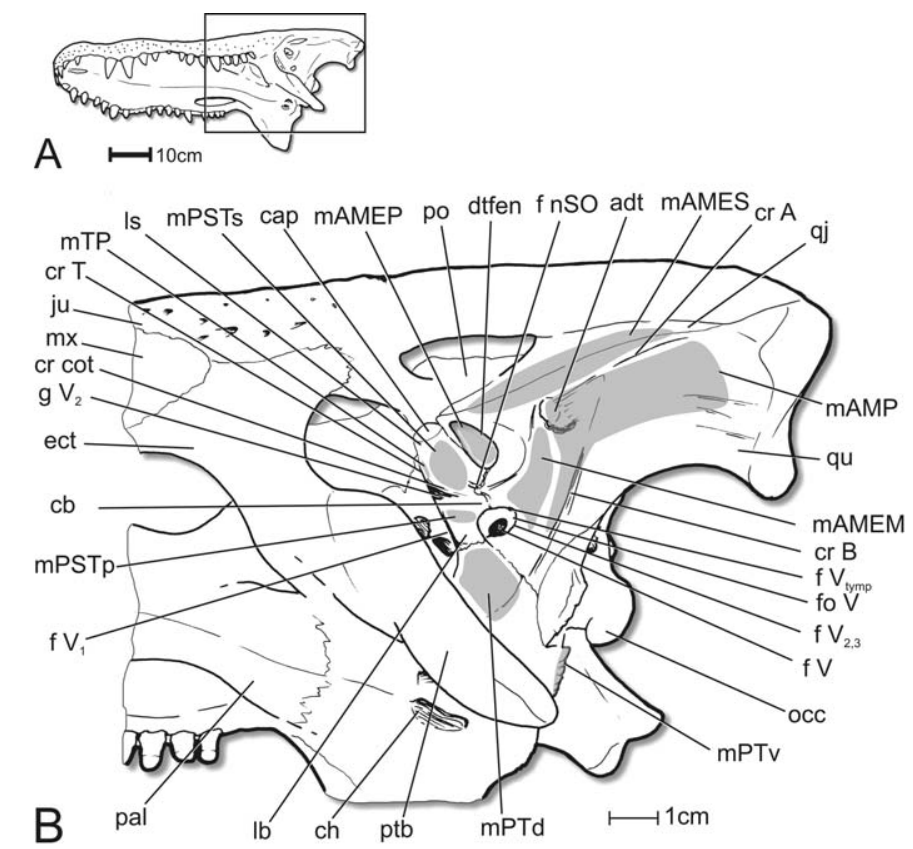

FIGURE 3. Overview of relevant osteological structures in extant crocodylians (e.g., Alligator mississippiensis OUVC 9640). A, Alligator skull in left ventrolateral view; $\mathbf{B}$, left ventrolateral view of orbitotemporal region highlighting areas of jaw muscle attachment, osteological correlates, and cranial bones. Illustration courtesy of R. Ridgely.

sphenoid lateral bridge (Iordansky, 1964; Brochu, 1999) descends from the postorbital process of the laterosphenoid and typically forms a laterally-overlapping suture with the pterygoid. This process separates the cavum epiptericum medially from the maxillary nerve and M. pseudotemporalis profundus laterally (Fig. 1). The caudal bridge of the laterosphenoid, a term introduced in this paper, separates the supraorbital nerve dorsomedially from the main trunk of the maxillary nerve ventrolaterally and is quite variable in size and shape (Figs. 1, 4, 5).

The neurovascular elements of the cavum epiptericum often excavate particular grooves on the main body of the laterosphenoid. These structures proceed in a dorsoventral progression: the ophthalmic nerve excavating the dorsal groove, with the rostral trigeminal artery and a branch of the vena capitis lateralis typically two more ventral grooves (Fig. 4A). The M. constrictor internus dorsalis nerve is small and does not substantially excavate the element. The lateral bridge typically has two osteological correlates on its lateral surface: the groove for the maxillary nerve dorsally, and some combination of a crest and fossa marking the attachment of M. pseudotemporalis profundus (Holliday and Witmer, 2007; = M. adductor mandibulae intermedius [Iordansky, 1964], M. pseudotemporalis [Busbey, 1989]) ventral to the nerve (Fig. 3).

The lateral and caudal bridges of the laterosphenoid exhibit marked variation in size and shape among extant crocodylians. Hatchlings of several taxa (e.g., Alligator mississippiensis, Crocodylus porosus, Gavialis gangeticus) do not possess either process, suggesting that these are likely secondarily developed structures. In individuals of many species (e.g., Crocodylus novaeguineae, C. porosus, Gavialis gangeticus, Paleosuchus palpebrosus, Tomistoma schlegelii), the lateral bridge is often subjected to excavation and erosion by the underlying vasculature of the cavum epiptericum. In some cases, the suture between the lateral bridge and the pterygoid is obliterated, and the bridge

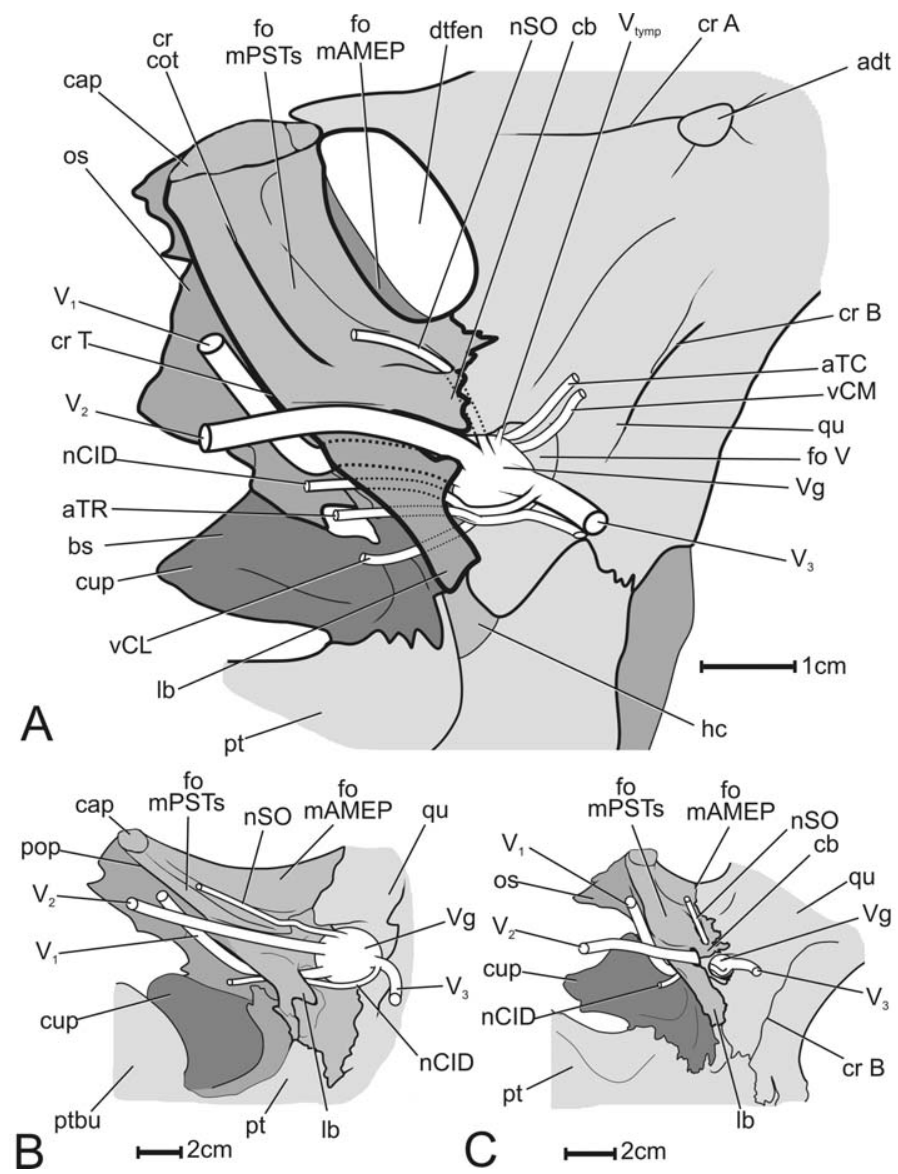

FIGURE 4. Variation in the trigeminal nerves and relevant structures in extant crocodylians. A, common morphology of the soft tissues and trigeminal foramen in the crocodylid Crocodylus porosus (FMNH 10865); B, reduced and excavated lateral and caudal lateral bridges in Gavialis gangeticus (MCZ R46551); C, hypertrophied lateral and caudal bridges in Crocodylus palustris (MCZ R4371).

subsides dorsally, leaving a thin isthmus or peninsula of bone (Iordansky, 1973; Fig. 4B). The size of the caudal bridge is also quite variable among extant crocodylians and even absent in some taxa (e.g., Osteolaemus tetraspis, Caiman latirostris, Voay robustus), although it is unclear if this is due to subsequent erosion rather than true absence. Alligator mississippiensis, $P$. palpebrosus, many Caiman species, and some crocodylids (e.g., C. novaeguineae) typically have short, robust caudal bridges that enclose the supraorbital nerve and articulate with the quadrate. The caudal bridge can be markedly elongate (e.g., Crocodylus acutus, C. niloticus), occasionally join with extra bony processes from the quadrate to enclose the exit of the caudal trigeminal artery, and in some extreme cases (e.g., Crocodylus palustris) form an additional bony bridge between the maxillary and mandibular nerves (Fig. 4C).

The postorbital process of the laterosphenoid is the main attachment site for M. pseudotemporalis superficialis (M. adductor mandibulae profundus pars anterior [Busbey, 1989]) in extant crocodylians (Holliday and Witmer, 2007). The muscle passes lateral to the maxillary nerve, medial to the supraorbital nerve, and attaches to the cartilago transiliens ventrally. The muscle often leaves a horizontal crest along the ventrolateral surface of the postorbital process. This is the 'cotylar crest' of Busbey (1989) or the 'longitudinal oblique crest' of Iordansky (1964), but not the 'cotylar crest' of Clark et al. (1993; Figs. 3, 4). 
Busbey (1989) first coined the term as the osteological correlate of the attachment for the rostral tendon of the anterior belly of M. adductor mandibulae externus profundus (mAMEP pars anterior), which Iordansky (1964) identified as the 'ls' tendon or the rostral tendon of his anterior belly of 'mAMEP', which was subsequently identified as the rostral aponeurosis of M. pseudotemporalis superficialis by Holliday and Witmer (2007). These
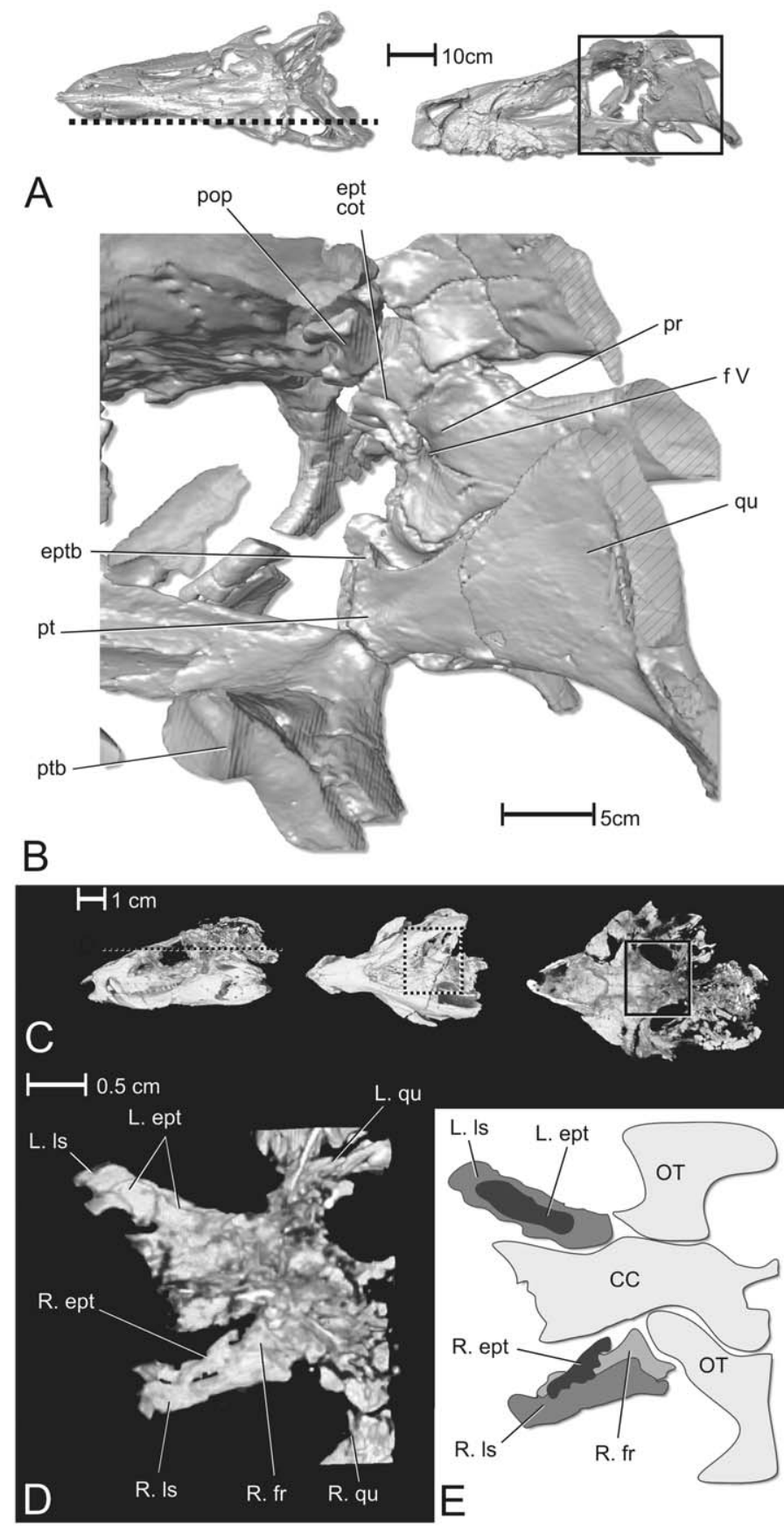

FIGURE 5. Orbitotemporal regions of the rauisuchian Saurosuchus galilei (PVSJ 32) and the protosuchian Protosuchus richardsoni (MCZ 6727) illustrated with CT data. A, dorsal and left lateral views of the skull of Saurosuchus showing location of oblique, parasagittal section; B, left lateral view of palate and braincase of Saurosuchus; $\mathbf{C}$, left lateral and ventral views of Protosuchus showing location of section and inset, and ventral view of horizontal section; $\mathbf{D}$, ventral view of dorsal half of skull showing ventral surfaces of laterosphenoids and epipterygoids in Protosuchus showing epipterygoid; $\mathbf{E}$, interpretive illustration of D. structures are homologous. However, Clark et al. (1993) synonymized the 'cotylar crest' of basal archosauriforms (e.g., Proterosuchus) with the laterosphenoid buttress (or antotic crest), the prominent ridge that separates the laterosphenoid into rostral (orbital) and caudal (temporal) surfaces, rather than an adductor muscle osteological correlate. Those authors further interpreted their 'cotylar crest' to lie rostral to the purported groove for the ophthalmic nerve in Proterosuchus (Clark et al., 1993:fig. 1, p. 51) which then would have passed through the dorsotemporal fossa onto the skull roof. This interpretation is likely not the case, because the ophthalmic nerve invariably passes along the orbital rather than the temporal surface of the laterosphenoid in archosauriforms.

The tensor crest forms the ventral part of the laterosphenoid buttress and is the attachment of the M. tensor periorbitae (M. levator bulbi dorsalis), the suborbital muscular sling innervated by the trigeminal nerve. This muscle leaves a small scar on the laterosphenoid buttress dorsolateral to the ophthalmic foramen and rostral to M. pseudotemporalis superficialis. In larger alligators, the rostral part of the cotylar crest partially merges with the ventral portion of the tensor crest to form a continuous, crescentic crest that starts ventrally along the dorsal edge of the maxillary nerve groove of the laterosphenoid lateral bridge and continues as the temporoorbital crest along the rostral edge of the laterosphenoid and across the ventral surface of the postorbital. However, this system of two confluent crests (i.e., cotylar crest plus tensor crest) is only found in Alligator. Other extant crocodylian taxa have a tensor crest, but not a marked cotylar crest, and instead have a large pseudotemporalis fossa along the caudodorsal surface of the laterosphenoid postorbital process (Figs. 3, 4).

Only M. adductor mandibulae externus profundus occupies the dorsotemporal fossa in extant crocodylians (Iordansky, 1964; Endo et al., 2002; Holliday and Witmer, 2007). This pattern differs from most lepidosaurian, avian, and basal crocodyliform taxa in which a combination of muscles, including $\mathrm{Mm}$. pseudotemporalis superficialis, adductor mandibulae externus profundus, and adductor mandibulae externus medialis occupy the region and are typically visible in dorsal view (Lakjer, 1926; Hofer, 1950; Haas, 1973; Holliday and Witmer, 2007). In extant crocodylians, M. adductor mandibulae externus profundus attaches to the ventromedial surface of the parietal but does not excavate the remainder of the dorsotemporal fossa proper. The dorsotemporal fenestra is largely vascular in nature. The fenestra and shallow ledge of the dorsotemporal fossa is excavated by the overlying temporoorbital branches of the stapedial artery, companion veins, and a relatively thick layer of areolar and connective tissue.

\section{The Basal Condition: Non-mesoeucrocodylian Suchians}

The epipterygoid is a consistent feature among archosauromorphs (e.g., Champsosaurus laramiensis, TMP 87.36.41; Scaphonyx sp., AMNH 7799), archosauriforms (e.g., Proterosuchus sp. [Clark et al., 1993; Klembara and Welman, 2007]; Chanaresuchus bonepartei, MCZ 4037; Proterochampsa barrionuevoi, MCZ 3408), phytosaurs (e.g., Paleorhinus sp., UC 632), rauisuchiforms (e.g., cf. Prestosuchus, MCZ 4167), and rauisuchians (e.g., Saurosuchus galilei, PVSJ 32 [Alcober, 2000], Arizonasaurus, MSM P4590). Among these taxa, the epipterygoid is typically a thin triangular element, arising from the dorsolateral edge of the pterygoid, articulating with the laterosphenoid (or the presumably membranous dorsolateral neurocranial wall and ventral part of the parietal in those taxa without a laterosphenoid) rostrodorsal to the trigeminal foramen and lateral to the groove for the ophthalmic nerve. The epipterygoid is broken dorsally in Saurosuchus and Arizonasaurus, but the ventral portion of the bone, as well as the cotyle for the articulation of that element with the laterosphenoid are present (Fig. 5B). 

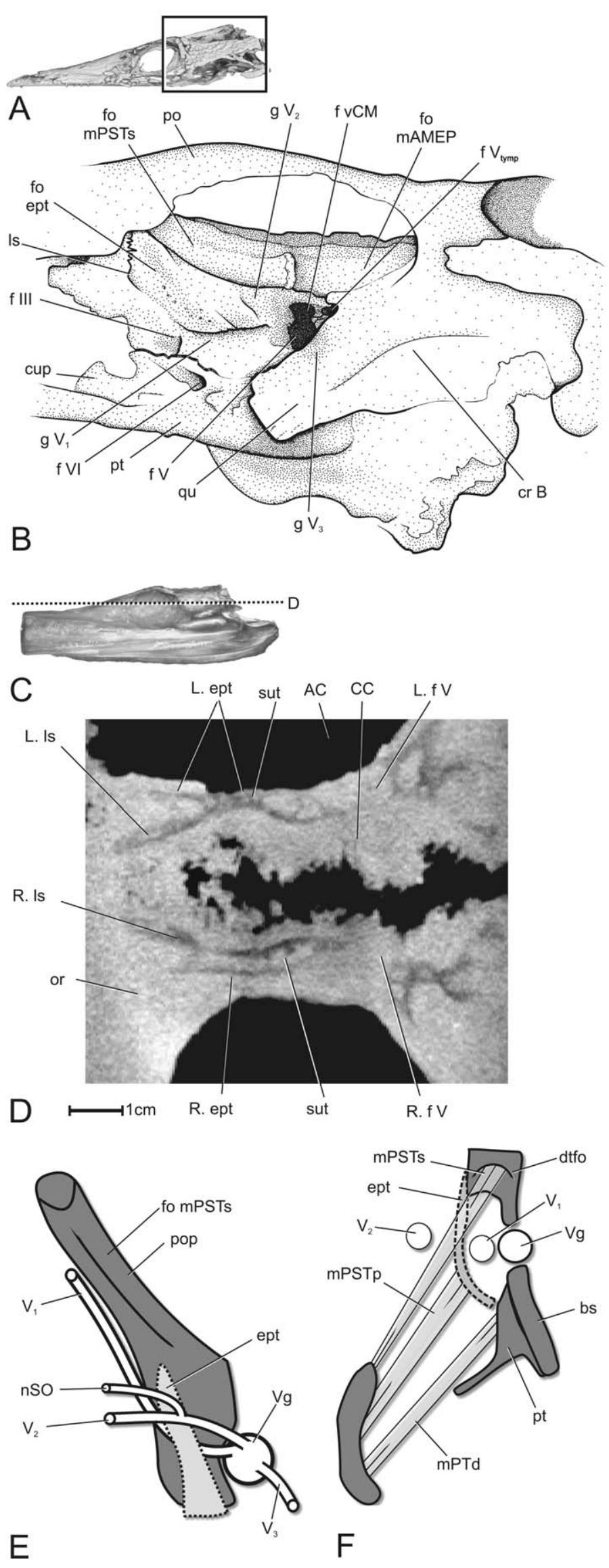

Walker (1990) described the left epipterygoid in the basal crocodylomorph Sphenosuchus acutus as an unusually dorsally situated, mediolaterally thin flange of bone situated rostrolateral to the trigeminal foramen and lateral to the ophthalmic groove (Walker 1990:fig. 25). He reconstructed the epipterygoid as arising from the dorsolateral surface of the pterygoid (Walker 1990: fig. 18), rostral to the dorsal wing of the quadrate process of the pterygoid, which is very similar to the condition in cf. Prestosuchus (MCZ 4167). The only robust, relevant osteological correlates for adductor chamber soft tissues in Sphenosuchus are the trigeminal foramen and a groove for the ophthalmic nerve. It is clear that the quadrates and pterygoids were not sutured to the braincase, and that the orbital process of the quadrate maintained a dorsolateral position relative to the pterygoid process of the quadrate.

The epipterygoid is present in protosuchians. CT data of Protosuchus richardsoni (MCZ 6727) indicate the presence of a short, mediolaterally flattened epipterygoid that articulates along the postorbital process of the laterosphenoid (Fig. 5D). The connection between the ascending process of the epipterygoid and its pterygoid articulation is damaged, obscuring some of its morphology. The protosuchian cf. Edentosuchus (UCMP 125358; Clark, 1994) also possesses an epipterygoid. However, only the pterygoid articulation of the element remains present on this specimen. The laterosphenoid is rostrocaudally broad and has a large pseudotemporalis fossa on its caudodorsal surface indicating $M$. pseudotemporalis superficialis occupied the rostral portion of the dorsotemporal fossa. However, there is no obvious articular cotyle for the epipterygoid. The pterygoid ramus of the quadrate forms a broad, overlapping articulation with the caudal portion of the pterygoid. The body of the pterygoid is obscured by matrix. However, the pterygoid process of the epipterygoid is visible as an overlapping suture just rostral to the trigeminal foramen. The basal crocodyliform Zosuchus davidsoni (IGM 100/1305) has a broad, smooth postorbital process of the laterosphenoid and a laterosphenoid buttress (Pol and Norell, 2004), but no lateral bridge. The only positive evidence for an epipterygoid is a shallow fossa caudoventral to the capitate process that may represent an epipterygoid cotyle. The trigeminal foramen enters into a shallow trigeminal fossa that is bounded rostromedially by a short, broken flange of the laterosphenoid body. A shallow groove excavates the lateral surface of the laterosphenoid indicating the course of the ophthalmic nerve.

\section{Mesoeucrocodylians}

Pelagosaurus typus-The basal thalattosuchian Pelagosaurus typus (BMNH R32599) (Eudes-Deslongchamps, 1863; Pierce and Benton, 2006) exhibits a unique temporal morphology compared to other mesoeucrocodylians (Fig. 6). Namely, the quadrate has an orbital process that remains free of bony attachment along its rostromedial surface, exhibiting a superficial resemblance to the neornithine quadrate orbital process or the quadrates of Sphenosuchus and other basal crocodylomorphs. In addition, the exceptional preservation of BMNH R32599 reveals most of the osteological correlates discussed in the remainder of the paper.

The large, irregularly-shaped, bilobate trigeminal foramen is bounded caudolaterally by the quadrate orbital process, caudomedially by the prootic, dorsally by the parietal, and rostrally by

$\leftarrow$ FIGURE 6. Orbitotemporal region and epipterygoid fossa of the mesoeucrocodylian Pelagosaurus typus. A, left lateral view of BMNH R32599 (CT-based surface) illustrating region of interest; $\mathbf{B}$, orbitotemporal region of BMNH R32599; C, left lateral view of BRLSI M1413 illustrating location of slice in $\mathrm{D} ; \mathbf{D}$, horizontal section through orbitotemporal region at the level of the trigeminal foramen in BRLSI M1413; $\mathbf{E}, \mathbf{F}$, schematics of Pelagosaurus as in Figure 1. 
the laterosphenoid. A number of neurovascular grooves exit the foramen and traverse the laterosphenoid rostrally, caudally, and dorsally. The ophthalmic nerve exits the rostroventral corner of the foramen and excavates a broad groove on the laterosphenoid body. The maxillary nerve exits the rostrodorsal corner of the trigeminal fossa and leaves a short, conical fossa ventral to the ventral margin of the dorsotemporal fossa. A slight depression on the quadrate orbital process suggests the passage of the mandibular nerve caudolaterally from the trigeminal foramen. The dorsal portion of the trigeminal foramen has a small groove that communicates with the otic region deep to the quadrate indicating the path of the tympanic branch of the trigeminal nerve.

Although the epipterygoid is not preserved in BMNH R32599, a large, rugose fossa marks the cotyle for the articulation of this element with the laterosphenoid. The laterosphenoid postorbital process, cotylar crest, pseudotemporalis fossa, and the tensor crest bound the dorsal and rostral margins of the large crescentic epipterygoid fossa (Fig. 6B). The bony morphology suggests a dense, fibrous attachment between the laterosphenoid and the epipterygoid. The caudalmost surface of the epipterygoid fossa is excavated by a short, conical groove for the maxillary division of the trigeminal nerve and a smooth, trapezoidal fossa marking the partial attachment for M. pseudotemporalis profundus. The ventral surface of the fossa extends ventrally as a large flange of bone overhanging the groove for the ophthalmic nerve and other soft-tissue structures of the cavum epiptericum. The ventral portion of the laterosphenoid is sutured to the basisphenoid, where a large foramen and associated groove exit the ventral part of the bone and merge with the groove for the foramen that transmitted the oculomotor nerve (cranial nerve III) and associated vasculature.

Complementing BMNH R32599, CT data of BRLSI M1413 reveal in situ epipterygoids on both sides of the specimen (Fig. 6D). The body of the element forms a broad, flat articulation with the postorbital process of the laterosphenoid with its rostralmost tip extending away from the laterosphenoid into the caudal part of the orbit. The gap between the rostral portion of the epipterygoid and the laterosphenoid suggests a large amount of soft tissue between the elements. The body of the epipterygoid sutures to the laterosphenoid rostral to the trigeminal foramen, potentially covering the ophthalmic nerve and cavum epiptericum, but does not appear to cover the foramen. Epipterygoid morphology is generally unclear in most of the other thalattosuchians examined. However, a dorsoventrally-compressed, uncatalogued AMNH specimen (cf. Mystriosaurus) possesses long, slender epipterygoids that have disarticulated from the laterosphenoid and are displaced into the temporal fossa. The elements lie between the dorsotemporal fenestra and pterygoid buttresses.

The laterosphenoid body in BMNH R32599 is rostrocaudally broad with a robust postorbital process (Fig. 6A). The laterosphenoid-prootic suture passes dorsally from the trigeminal fossa and forms a pronounced dorsoventrally long protuberance which divides the dorsotemporal fossa into caudal and rostral fossae suggesting the attachments of at least two muscles, here interpreted to have been M. adductor mandibulae externus profundus and M. pseudotemporalis superficialis, respectively. Alternatively, it could be hypothesized that bellies of M. adductor mandibulae externus, including profundus and medialis bellies were the dominant muscles of the skull roof. However, several lines of evidence suggest that this is not likely the case.

First, the caudodorsomedial surface of the dorsotemporal fossa is marked by a large vascular groove, the osteological correlate of vessels originating from the stapedial artery and the dural venous sinuses. The temporoorbital artery and accompanying veins pass rostrolaterally between $\mathrm{Mm}$. pseudotemporalis superficialis and adductor mandibulae externus profundus among most reptiles (Oelrich, 1956; Haas, 1973; Vanden Berge and
Zweers, 1993; Holliday and Witmer, 2007), and the vessels thus serve as strong topological criteria for assessing homologies. Because the groove passes rostrally along the surface of the parietal, it is reasonable to infer that $M$. adductor mandibulae externus profundus most likely attached to the caudomedial corner of the dorsotemporal fossa, thereby appressing the vessels against the wall of the fossa. The muscle would have entered the ventral portion of the temporal fossa near the caudal surface of the laterosphenoid-prootic suture. There is not a clear extension of the temporoorbital groove along the rostromedial surface of the dorsotemporal fossa suggesting that, if the same soft-tissue topology as that found in extant reptilians applies to Pelagosaurus, the vessel then likely departed from the wall of the fossa and continued rostroventrolaterally into the temporal region, caudolateral to M. pseudotemporalis superficialis to then ramify along the caudal wall of the orbit. Thus, if M. adductor mandibulae externus profundus occupied the rostral portion of the dorsotemporal fossa, it would be expected that the groove for the temporoorbital artery would circumscribe the entire medial and rostral surface of the dorsotemporal fossa.

Second, the groove for the mandibular nerve on the orbital process of the quadrate also indicates that the interface between M. pseudotemporalis superficialis and M. adductor mandibulae externus profundus occurred along the plane formed by the trigeminal foramen and the protuberance in the dorsotemporal fossa. If $\mathrm{M}$. adductor mandibulae externus profundus occupied the rostral portion of the skull roof, it would be expected that mandibular nerve first passed rostrally and medial to $M$. adductor mandibulae externus profundus before wrapping laterally around the muscle to then pass caudoventrolaterally towards the caudal portion of the mandibular fossa, basically making a $180^{\circ}$ turn just caudal to the orbit.

Third, the presence of an epipterygoid in BRLSI M1413 and an epipterygoid fossa in BMNH R32599 suggests that M. pseudotemporalis profundus, which consistently attaches across the lateral surface of the epipterygoid in lizards, may also have been large compared to that found in extant crocodylians. Thus, if M. pseudotemporalis profundus attached to most of the postorbital process of the laterosphenoid, via the epipterygoid, then $\mathrm{M}$. pseudotemporalis superficialis most likely occupied the rostral portion of the dorsotemporal fossa.

Therefore, the caudomedial lamina of M. pseudotemporalis superficialis most likely attached to the rostrolateral surface of the parietal and caudodorsal surface of the laterosphenoid, thus occupying the entirety of the caudodorsal surface of the laterosphenoid, excavating the pseudotemporalis fossa (Fig. 6C). This morphology is consistent among other thalattosuchian taxa such as Mystriosaurus (UC 402) and Metriorhynchus (AMNH 997) which also have dorsally exposed laterosphenoids with distinct muscular fossae in the rostral part of the dorsotemporal fossa. This condition (an intrafenestral M. pseudotemporalis superficialis) is shared with many lepidosaur taxa, but not with extant crocodylian taxa and other mesoeucrocodylians in which the pseudotemporalis fossa, its musculature, and laterosphenoid have migrated to a subfenestral position.

Simosuchus clarki-The mesoeucrocodylian Simosuchus clarki (UA 8679) appears to have possessed a short epipterygoid (Fig. 7A). However, the body of the element on the right side of the specimen is missing, leaving only its dorsal (laterosphenoid) and ventral (pterygoid) articulations. The trigeminal foramen is small and circular with a large dorsoventrally ovate trigeminal fossa that opens ventrally into a large maxillomandibular groove. A distinct ophthalmic groove exits the rostrodorsal margin of the trigeminal fossa and courses medial to the dorsal part of the epipterygoid and then rostral to the sharp laterosphenoid buttress.

Araripesuchus-The mesoeucrocodylian Araripesuchus sp. (e.g., AMNH 24450, UC specimen; Ortega et al., 2000; Pol and Apesteguia, 2005; Turner, 2006) has a completely sutured pala- 


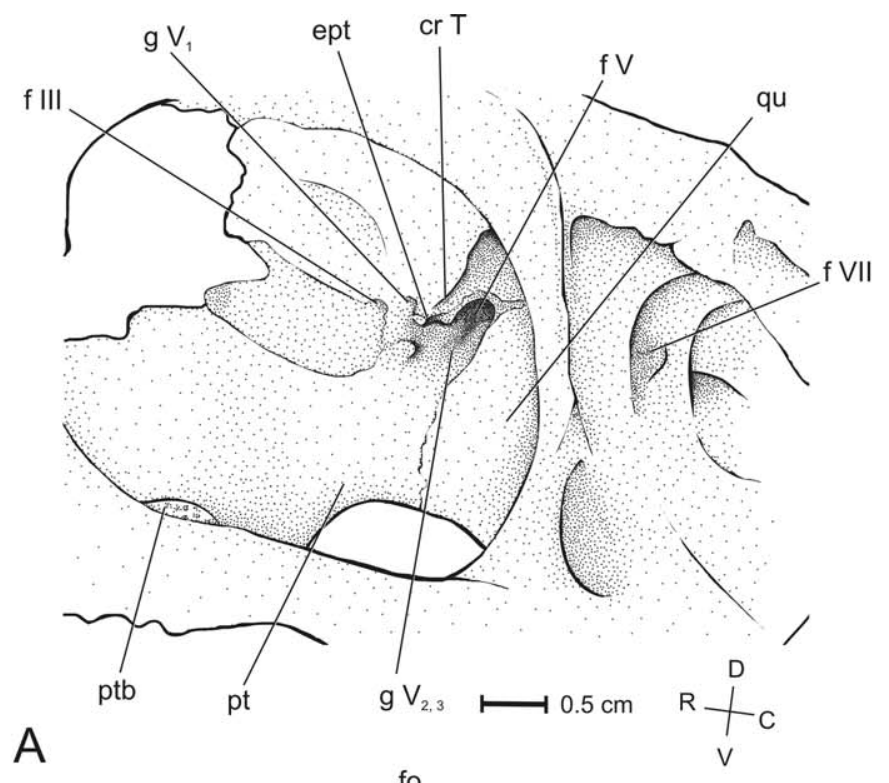

A

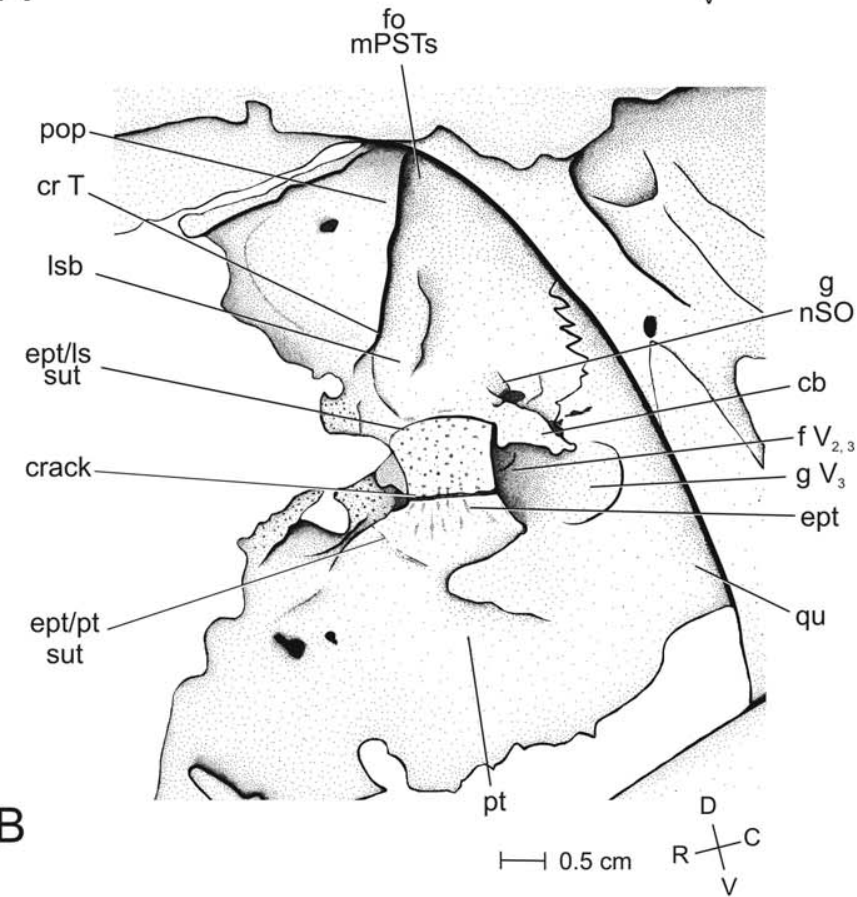

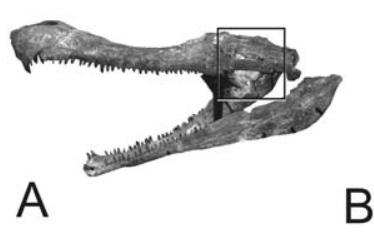
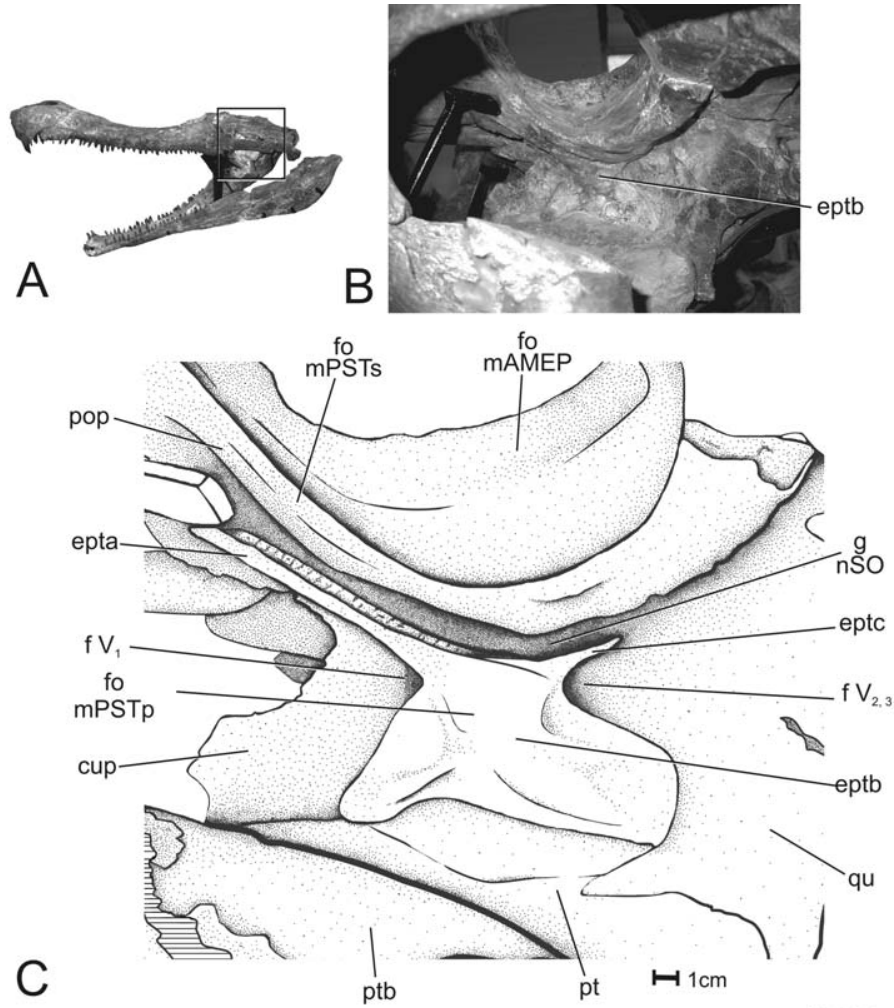

C
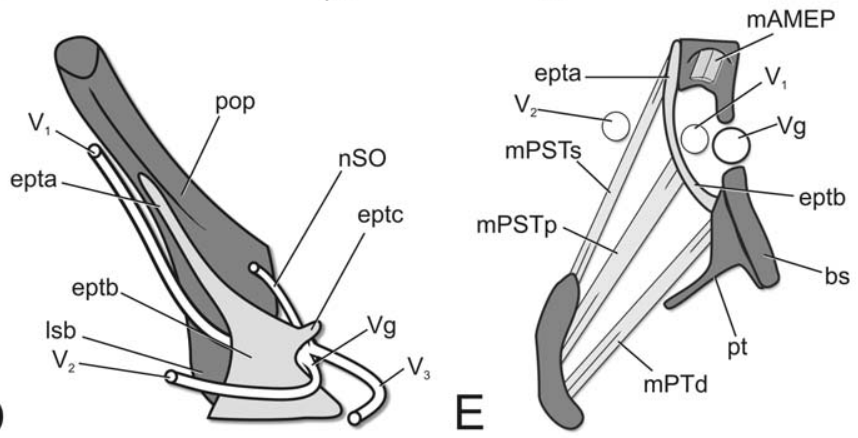

FIGURE 8. Orbitotemporal region of the neosuchian Sarcosuchus imperator (MNN 604). A, reference photo of specimen indicating temporal region; $\mathbf{B}$, photograph of temporal region in left lateral view with in situ large, triradiate epipterygoid overlapping the laterosphenoid and covering the trigeminal foramen; $\mathbf{C}$, illustration of orbitotemporal region in left lateral view; $\mathbf{D}, \mathbf{E}$, schematics of Sarcosuchus as in Figure 1.

tocranial junction and a prominent epipterygoid (Fig. 7B). The mediolaterally thin, rostrocaudally waisted epipterygoid extends dorsally from a slightly raised, rostrocaudally directed pterygoepipterygoid articulation (Fig. 7B, D). The caudal edge of the element laterally bounds the rostral margin of the maxillomandibular foramen, whereas the rostral rim forms the foramen for the ophthalmic nerve and its adnexa. Dorsally, the epipterygoid is sutured to the laterosphenoid, leaving a raised and crescentic

$\leftarrow$ FIGURE 7. The orbitotemporal regions and epipterygoid of mesoeucrocodylians in left oblique lateral views. A, Simosuchus clarki (UA 8679) showing broken epipterygoid and relevant structures in left oblique rostrolateral view; B, Araripesuchus sp. (AMNH 24450) showing waisted epipterygoid and relevant structures; $\mathbf{C}, \mathbf{D}$, schematics of orbitotemporal regions of specimens as in Figure 1. 
ridge. A distinct, conical, smooth fossa extends caudoventrally from the maxillomandibular foramen indicating the exit and direction of these two trigeminal divisions (Fig. 7B).

Similar suites of crescentic, raised sutures between a waisted epipterygoid and the laterosphenoid are also present in other

A
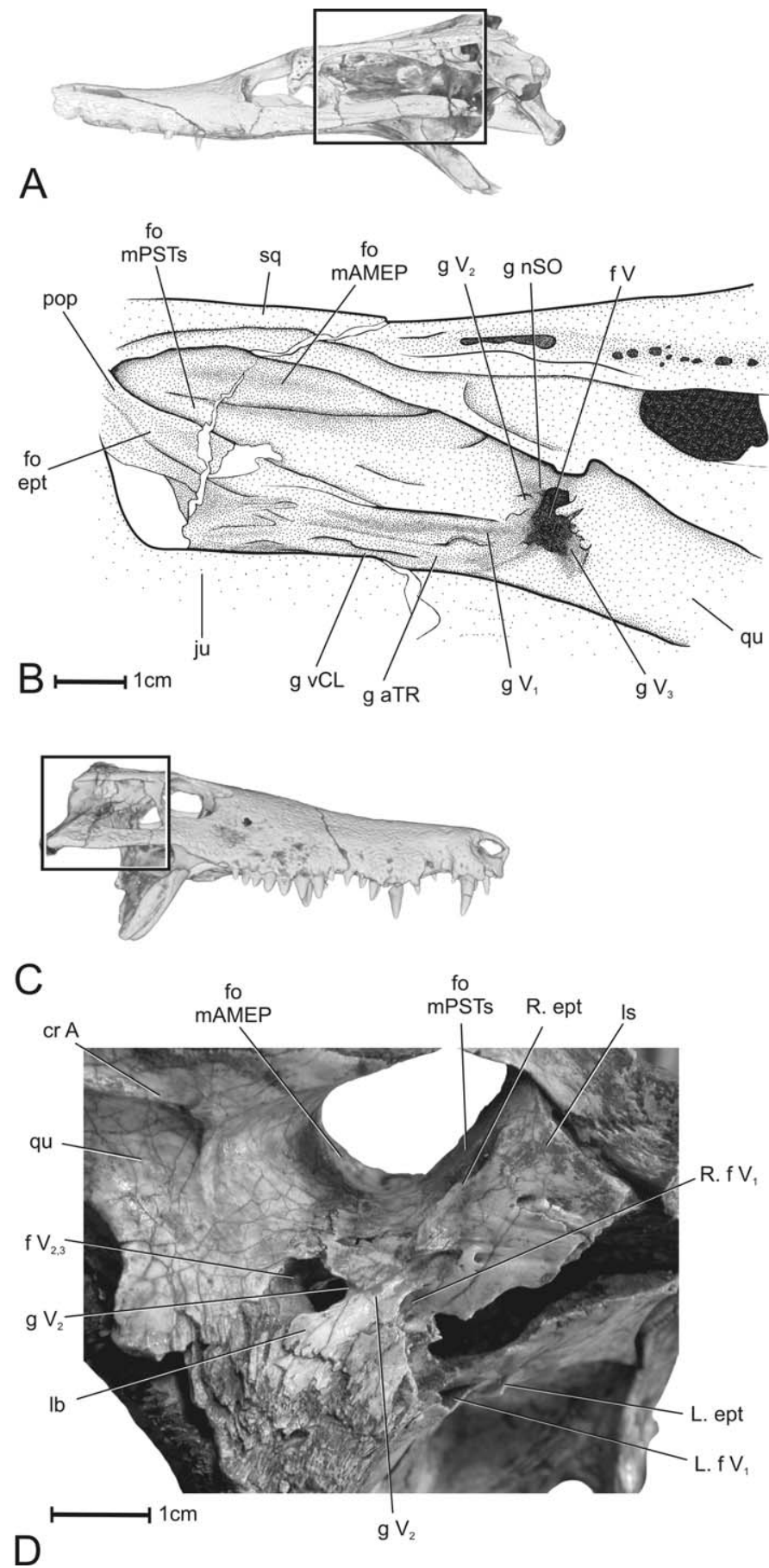

FIGURE 9. Orbitotemporal regions of the dyrosaur cf. Rhabdognathus and the sebecid Hamadasuchus rebouli. A, reference image based on CT data of cf. Rhabdognathus in left lateral view indicating temporal region; B, illustration of the orbitotemporal region of cf. Rhabdognathus (CNRST-SUNY-190) illustrating neuromuscular osteological correlates and epipterygoid fossa in left lateral view; $\mathbf{C}$, reference image based on CT data of Hamadasuchus (ROM 52620) in right lateral view, indicating temporal region; D, photograph of isolated Hamadasuchus braincase (ROM 54511) indicating epipterygoid, lateral bridge, and other orbitotemporal structures in right ventrolateral view.
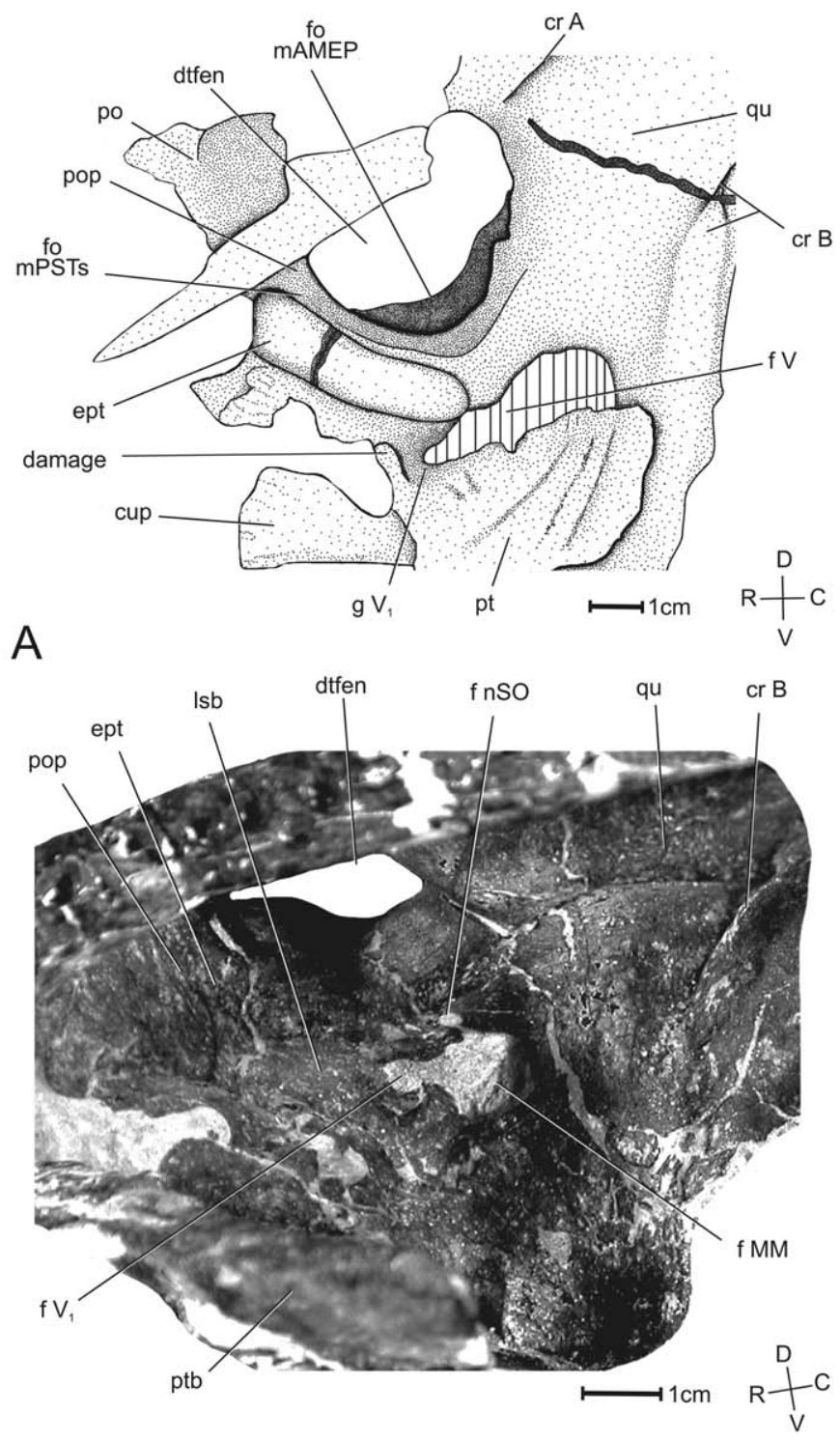

$\mathrm{B}$

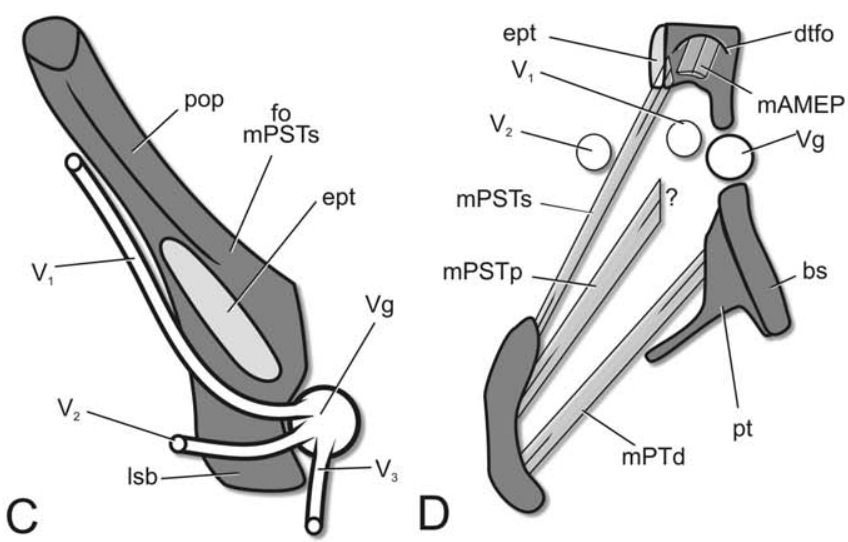

FIGURE 10. Orbitotemporal regions of the neosuchians Goniopholis lucasii and Eutretauranosuchus illustrating isolated epipterygoid sutured to postorbital process of laterosphenoid. A, illustration of orbitotemporal region of Goniopholis (AMNH 5782) in left ventrolateral view; B, photograph of orbitotemporal region of Eutretauranosuchus (CMNH 8208) in left ventrolateral view indicating fragment of epipterygoid; $\mathbf{C}, \mathbf{D}$, schematics of isolated epipterygoid morphotype present in Goniopholis, Eutretauranosuchus, and Hamadasuchus as in Figure 1. 
mesoeucrocodylian taxa including Mahajungasuchus insignis (FMNH PR99182) and an undescribed crocodyliform from Niger (Sereno et al., 2004). Araripesuchus appears to be the most basal taxon to possess a caudal bridge of the laterosp- henoid. The slightly damaged flange of bone extends caudoventrally from the laterosphenoid, without contacting the epipterygoid, and overhangs the dorsal part of the maxillomandibular foramen, almost contacting the prootic caudally as a

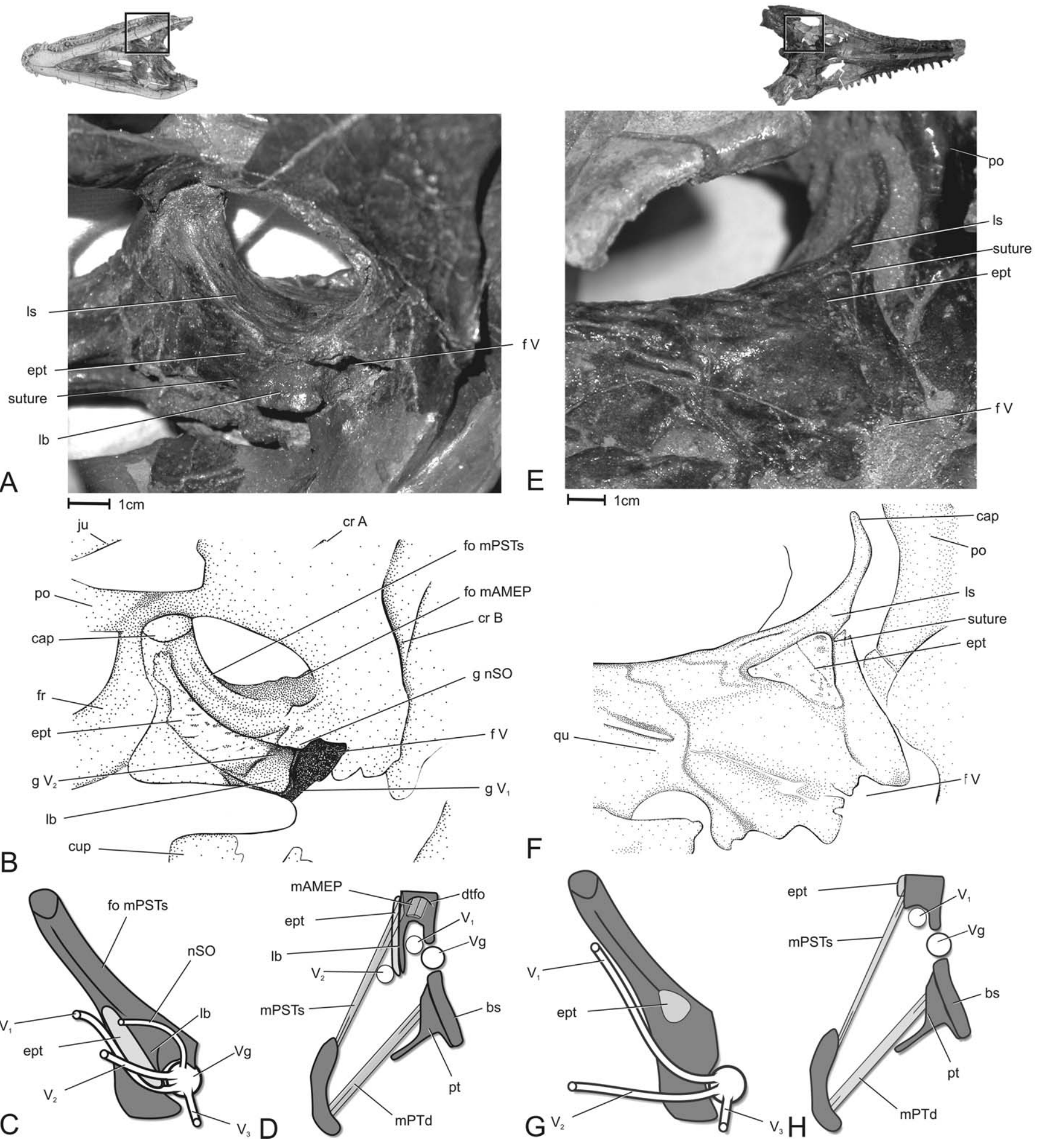

FIGURE 11. Orbitotemporal region of the eusuchian Leidyosuchus canadensis and Eosuchus minor. A, reference image based on CT data of Leidyosuchus (ROM 1903) in left ventrolateral view and photograph of CMN 8942; B, illustration of Leidyosuchus (CMN 8942) in left ventrolateral view illustrating neurovascular osteological correlates, epipterygoid, and lateral bridge of the laterosphenoid; C, D, schematics of isolated epipterygoid morphotype present in Leidyosuchus as in Figure 1; E, reference image of Eosuchus minor (USMN 181577) in ventral view and photograph of right orbitotemporal region in right ventral view showing isolated epipterygoid and laterosphenoid (specimen is dorsoventrally compressed); $\mathbf{F}$, illustration of right orbitotemporal region highlighting isolated epipterygoid; G, H, schematics of isolated epipterygoid morphotype present in Eosuchus as in Figure 1. 
thin triangular process. A distinct supraorbital foramen also opens dorsal to the caudal bridge in both AMNH 24450 and the Nigerian specimen of Araripesuchus (Sereno et al., 2004). Araripesuchus, Mahajungasuchus, and Simosuchus all possess dorsotemporal fossae that possess only one muscle, M. adductor mandibulae externus profundus. In each case, the absence of a fossa on the dorsal surface of the laterosphenoid clearly indicates that M. pseudotemporalis superficialis did not attach within the dorsotemporal fossa.

Sarcosuchus imperator-The neosuchian Sarcosuchus imperator (MNN 604) from Cretaceous northern Africa (Sereno et al., 2001) has a large, overlapping epipterygoid. The element is mediolaterally thin and lies along the ventrolateral surface of the laterosphenoid, rostroventral to the dorsotemporal fossa (Fig. 8). A long ascending ramus articulates along the lateral surface of the postorbital process of the laterosphenoid and abruptly terminates as a mediolaterally flat, subcircular process, rostroventral to the capitate process (Fig. 8). Ventrally, the element appears to be sutured to the dorsal process of the rostrocaudally elongate pterygoid and the dorsal part of the pterygoid ramus of the quadrate.

The epipterygoid body is rostrocaudally waisted similar to that found in Araripesuchus. The rostral portion of the body forms the lateral wall of the ophthalmic foramen and cavum epiptericum (Fig. 8C). The rostral edge of the epipterygoid body overhangs the lateral surface of the cultriform process. The caudal margin of the epipterygoid body, dorsal to the

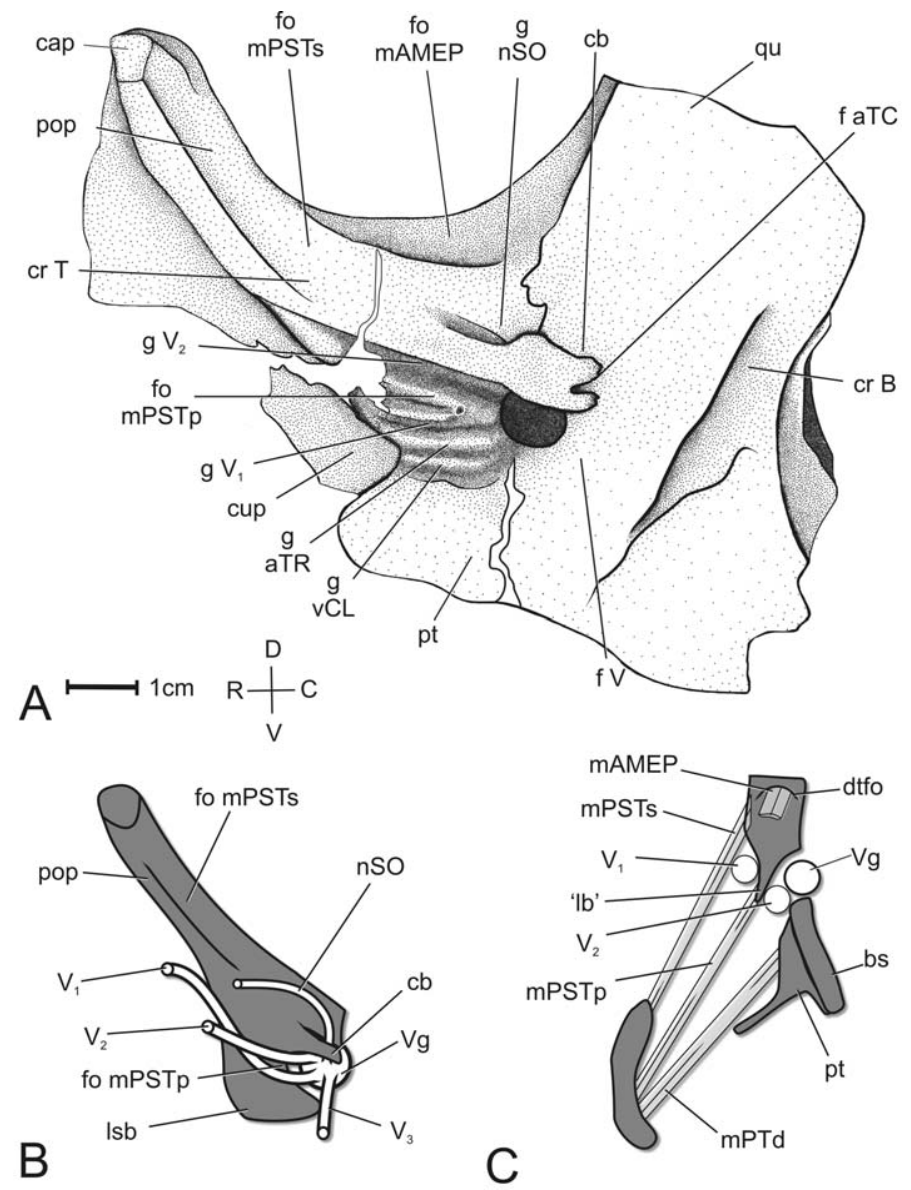

FIGURE 12. Orbitotemporal region of the eusuchian Gryposuchus columbianus (UCMP 38358) illustrating neurovascular osteological correlates and absence of epipterygoid-related features. $\mathbf{A}$, illustration of orbitotemporal region in left lateral view; $\mathbf{B}, \mathbf{C}$, schematics of isolated epipterygoid morphotype present in Gryposuchus as in Figure 1. element's quadrate articulation, overhangs a large, caudally directed, crescentic maxillomandibular foramen. The prootic forms the caudomedial wall of the maxillomandibular foramen. A short, triangular process of the epipterygoid extends caudodorsally over the maxillomandibular foramen and laterally bounds the supraorbital canal, which extends rostrodorsally from the maxillomandibular foramen and then passes along the margin between the postorbital process and the laterosphenoid (Fig. 8C).

The laterosphenoid has a large fossa on its caudoventral surface below the dorsotemporal fossa indicating the presence of a subfenestral M. pseudotemporalis superficialis. The extent of musculature on the epipterygoid is difficult to infer due to the lack of robust, muscular osteological correlates. However, M. pseudotemporalis profundus likely attached to it. The maxillary nerve clearly initially passes caudally out of the maxillomandibular foramen, indicating the presence of a large amount of muscular tissue (e.g., mm. pseudotemporalis superficialis and profundus) rostral to the maxillomandibular foramen, prohibiting the nerve from excavating the epipterygoid, as found with the maxillary nerve and laterosphenoid lateral bridge in extant taxa (Figs. 4, 8D).

Additional specimens of Sarcosuchus (e.g., ROM 52586, CMN 51257) are missing the epipterygoids, revealing the underlying morphology of the trigeminal foramen and surrounding structures. The irregularly-shaped foramen is similar to that of Pelagosaurus and has distinct ophthalmic and maxillomandibular grooves exiting the rostral and caudal margins of the foramen, respectively. A third, smaller groove for the supraorbital nerve exits the dorsal margin of the foramen. Rostral to the supraorbital foramen, a long, slender, shallow fossa on the postorbital process of the laterosphenoid is present where the ascending process of the epipterygoid once articulated. In CMN 51257, the body of the epipterygoid would have enclosed the ophthalmic canal. However, the rest of the element is missing, obscuring the nature of its relationships to the other structures.

Dyrosauridae - The dyrosaurid cf. Rhabdognathus (CNRSTSUNY-190; Brochu et al., 2002) has a markedly rostrocaudally elongate laterosphenoid excavated by a number of neurovascular grooves exiting a large, irregularly shaped trigeminal foramen (Fig. 9A, B). Brochu et al. (2002:1066) recognized the grooves to be for "branches of the trigeminal nerve." More specifically, the grooves represent, from dorsal to ventral, the ophthalmic nerve, rostral trigeminal artery, and the trigeminal branch of vena capitis lateralis. These three grooves originate from a single, larger groove in the rostroventral corner of the trilobate trigeminal foramen. The supraorbital and maxillary nerves exit the rostrodorsal corner of the trigeminal foramen, leaving a short shallow groove on the laterosphenoid. The maxillary groove lies caudal to a large triangular fossa for M. pseudotemporalis superficialis. This muscle lies ventral to the $\mathrm{M}$. adductor mandibulae externus profundus, which occupies the dorsotemporal fossa. The epipterygoid fossa is situated diagonally on the rostrolateral surface of the postorbital process, rostral to the pseudotemporalis fossa. Jouve (2005) redescribed the braincase of Dyrosaurus phosphaticus as possessing a laterosphenoid lateral bridge. Although not included in Jouve's (2005) interpretation, a noticeably large fossa on the laterosphenoid suggests that an epipterygoid similar in morphology to Pelagosaurus and Sarcosuchus may have also been present.

Hamadasuchus rebouli-The neosuchian Hamadasuchus rebouli (ROM 52620, 54511, 54513; Larsson and Sues, 2007) has a rostrocaudallylong laterosphenoid lateral bridge that sutures to the pterygoid. However, only a referred, isolated braincase (ROM 54511; Figs. 9C, D) provides evidence of an epipterygoid. On the lateral surface of the postorbital process of the laterosphenoid of ROM 54511, a structure similar to the ascending process of the epipterygoid in other taxa (e.g., Sarcosuchus, 


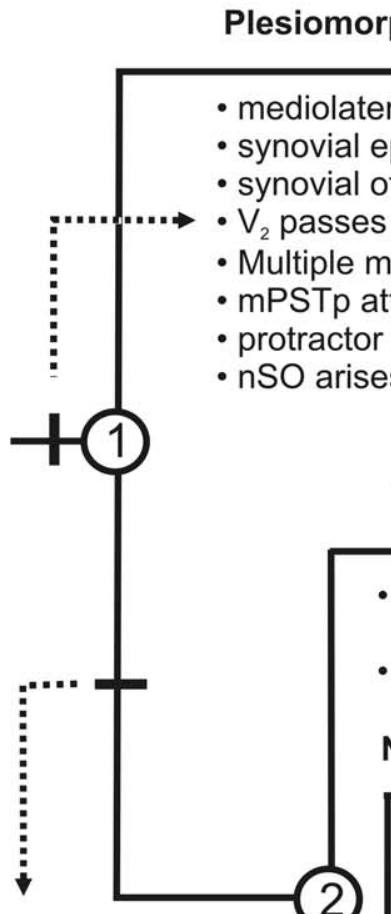

- synovial ept-ls joint eliminated

- pterygoid completely sutured to braincase

- protractor muscles absent

- epipterygoid ascending process sutured to lateral surface of laterosphenoid
- caudolaterally directed $\mathrm{V}_{2}$

- nSO separate from $\mathrm{V}_{2}$

- quadrate completely sutured to braincase

- one muscle (mAMEP) in temporal fossamPSTs subfenestral
Overlapping: Pelagosaurus

- quadrate incompletely sutured

to braincase

- two muscles in dorsotemporal fossa

Non-overlapping: Columnar: Simosuchus - columnar, non-overlapping epipterygoid

Non-overlapping: Waisted: Araripesuchus

- waisted, non-overlapping epipterygoid

- epipterygoid sutured to ventral process of laterosphenoid

- caudal bridge present
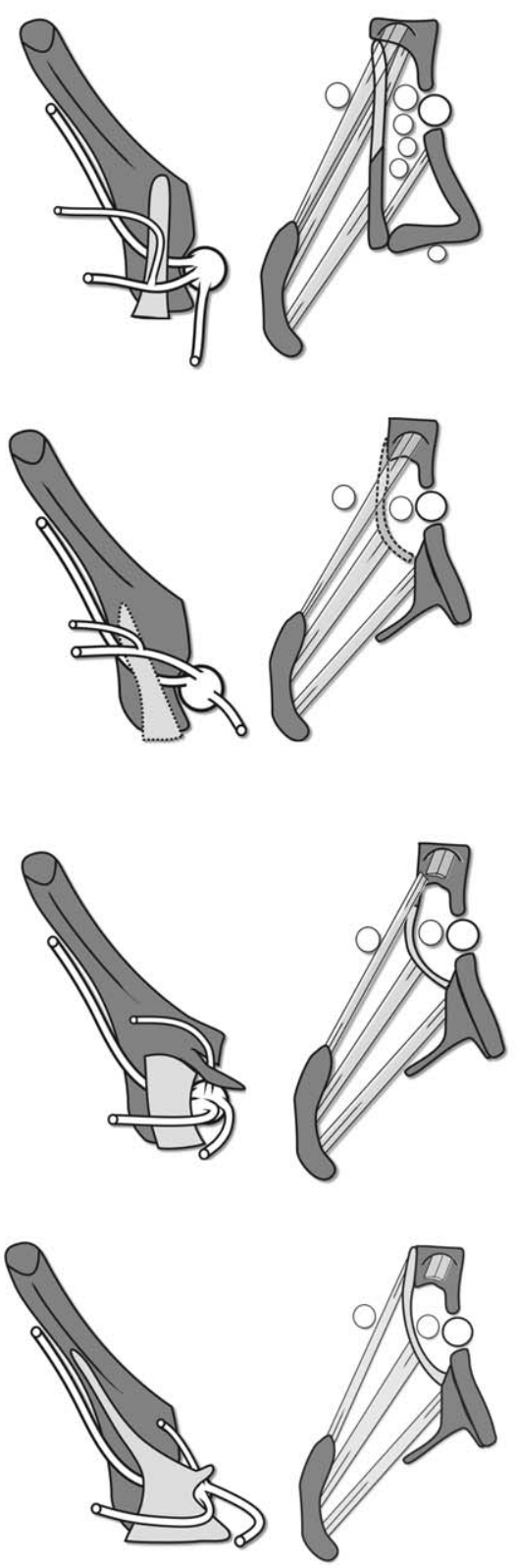

Overlapping: Rhabdognathus

Overlapping: Sarcosuchus

- large, triradiate epipterygoid

- caudal bridge absent

rostrocaudally broad epipterygoid with thin ascending process

- rostrodorsolaterally-directed $V_{2}$

(3)

- epipterygoid uncoupled from pterygoid

- cavum epiptericum exposed laterally
Isolated: Goniopholis
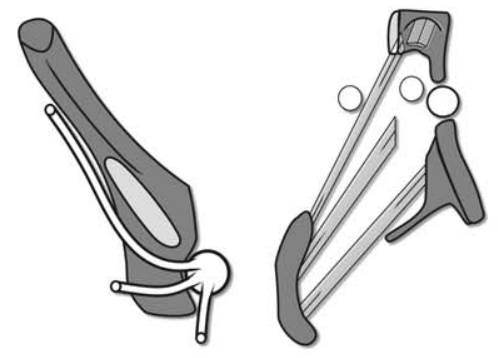

Eusuchia

(continued on Fig. 14) 
Goniopholis) is apparently fused to the laterosphenoid, whereas its dorsal surface is free of bony attachment, giving the element the appearance of a large, thin flange (Fig. 9C, D). However, because the other specimens do not show any evidence of this element, the unique morphology of ROM 54511 proves to be problematic. The morphology of the maxillomandibular foramen in all specimens indicates that the maxillary nerve initially exited the foramen caudally as in Sarcosuchus, Simosuchus, and Araripesuchus. The morphology of the dorsotemporal fossa and laterosphenoid body indicates that M. pseudotemporalis superficialis attached to the caudal surface of the laterosphenoid ventral to the dorsotemporal fossa and that only $\mathrm{M}$. adductor mandibulae externus profundus occupied the dorsotemporal fossa.

Goniopholididae-The neosuchian Goniopholis lucasii (AMNH 5782, AMNH 570, CM 1339) exhibits significant changes in the lateral wall of the braincase compared to the above taxa. In both AMNH 5782 and AMNH 570, a rostrocaudally long, dorsoventrally thin, ovate, isolated epipterygoid sutures to the lateral surface of the laterosphenoid (Fig. 10). The rostrodorsal part of the epipterygoid terminates ventral to the capitate process and the caudoventral part of the epipterygoid terminates rostrodorsal to the trigeminal foramen. Both the dorsal and ventral edges of the element are complete, smooth, and undamaged. However, this element fails to bridge the rostral part of the trigeminal foramen (Fig. 10). Although the trigeminal foramen is slightly obscured by matrix, the ophthalmic groove is present exiting the rostral edge of the trigeminal fossa, lateral to the main body of the laterosphenoid. Thus, it is clear that the cavum epiptericum is laterally exposed and bounded by unpreserved soft tissues rather than bone. The epipterygoid is slightly displaced ventrally in AMNH 5782 revealing the underlying laterosphenoid, whereas the element is displaced more caudoventrally in AMNH 570. Given that other neighboring elements are not severely distorted in these specimens, the displacement of these epipterygoid elements indicates that they may not have been firmly sutured to the laterosphenoid postorbital process in life.

In the related neosuchian Bernissartia fagesii (IRScNB ${ }^{\circ} \mathrm{R}$ 46; Norell and Clark, 1991), a similar, slender, triangular element is also present, lying lateral to the laterosphenoid. However, the position of this element relative to the trigeminal foramen and relevant structures is uncertain due to poor preservation. The goniopholidid Eutretauranosuchus (CMNH 8208) also has a single, bilobate trigeminal foramen, a separate supraorbital foramen, and no lateral bridge (Fig. 10B). These structures are similar to those in Goniopholis. In addition, a slender fragment of an epipterygoid lies along the rostroventral margin of the ascending process of the laterosphenoid. The dorsotemporal fossae of Goniopholis, Bernissartia, and Eutretauranosuchus are all circular in shape and have limited contribution from the laterosphenoid. This suggests that M. pseudotemporalis superficialis had migrated to a subfenestral position and M. adductor mandibulae profundus occupied the entire fossa in these eusuchian sister taxa.

\section{Eusuchians}

Leidyosuchus canadensis-The Late Cretaceous alligatoroid Leidyosuchus canadensis (Brochu 1997, 1999; Wu et al., 2001) is represented by several specimens with preserved braincases (ROM 1903, USNM 6533, TMP 83.25.03, CMN 8942), of which the last two clearly possess small, flat, isolated epipterygoids on the lateral surface of the postorbital process of the laterosphe- noid. The epipterygoid is similar in size and shape to that in Goniopholis, but differs in that the rostrodorsal edge is sutured to the laterosphenoid via several small bony projections. In CMN 8942, the element continues caudoventrally as a flat, quadrangular element and terminates at the rostrodorsal corner of the maxillomandibular foramen (Figs. 11 A, B). Although the region is damaged, the lateral surface of the epipterygoid is concave, indicating the path of the maxillary nerve, and the caudoventral margin of the epipterygoid fuses onto a thin bony lamina, the lateral bridge of the laterosphenoid, which encroaches over part of the ophthalmic canal.

In a different Leidyosuchus specimen (TMP 83.25.03), the epipterygoid terminates considerably more ventrally on the laterosphenoid than that in CMN 8942 and has a distinct maxillary groove on the caudoventral corner of the element. Medial to the epipterygoid is an underlying secondary bony lamina of the laterosphenoid. If not for the overlying epipterygoid, this lamina would be topologically in the same position as the lateral bridge. In USNM 6533, the epipterygoid is missing, revealing a moderately deep, rectangular fossa that lies ventral to the dorsotemporal fossa and extends rostrodorsally along the postorbital process of the laterosphenoid. These fossae are similar to those found on the laterosphenoids of Hylaeochampsa vectiana (BMNH R177) and Borealosuchus sternbergii (UCMP 126099). On the other hand, TMP 96.12.74 appears to be missing the epipterygoid, but the lateral surface of the laterosphenoid is flat.

These variations in temporal morphologies among Leidyosuchus individuals may be ontogenetic in origin (Wu et al., 2001). Nevertheless, they do indicate that the epipterygoid was a robust feature of the skull and that the lateral bridge may not have been as completely developed as seen in extant crocodylians. More importantly however, this is the first clear example of a taxon that has both an epipterygoid and a laterosphenoid lateral bridge. These co-occurring structures violate the homology test of conjunction (Patterson, 1982) which states that putative homologs cannot co-occur in the same individual. Therefore, the epipterygoid and laterosphenoid lateral bridge are analogous structures in which the latter replaces the topological position of the former in the orbitotemporal region.

Eosuchus minor-The Paleocene gavialoid Eosuchus minor (USNM 181577) has a rostrocaudally elongate laterosphenoid that has a crecentric sulcus on its lateral surface (Brochu, 2006). The region surrounding the trigeminal foramen is damaged, obscuring clear evidence of a lateral bridge and the laterosphenoidpterygoid suture. However, a small, flat triangular epipterygoid is located on the postorbital process of the laterosphenoid (Figs. 11E, F). The element has a dimpled surface and elevated rounded edges that separate it from the shallow fossa in which it sits on the laterosphenoid. The caudal edge of the epipterygoid clearly terminates dorsal to the pterygoid attachment of the laterosphenoid and also does not cover the ophthalmic groove similar to the morphology of the element in Goniopholis.

Gryposuchus columbianus-The Miocene gavialoid Gryposuchus columbianus (UCMP 38358; Langston and Gasparini, 1997; Brochu, 1997, 2004) is represented by a well-preserved dorsal half of the braincase including the skull table, rostral part of the quadrate, laterosphenoid, and dorsal parts of the basisphenoid and the pterygoid (Fig. 12). On the left side, the laterosphenoid is sculpted by four different grooves rostral to the trigeminal foramen. Langston and Gasparini (1997) identified two of the four grooves as the osteological correlates of the ophthalmic nerve and recurrent branch of the internal carotid artery (rostral trigeminal artery of Sedlmayr [2002]). The ventral groove is

\footnotetext{
$\leftarrow$ FIGURE 13. Evolution of the epipterygoid, laterosphenoid, and orbitotemporal region in mesoeucrocodylians. A, cladogram of representative non-eusuchian crocodyliform taxa illustrating major character transitions in the orbitotemporal region during crocodilian evolution; $\mathbf{B}, \mathbf{C}$, summary of schematics of focal taxa as in Figure 1. Clades: 1, Crocodylomorpha; 2, Mesoeucrocodylia; 3, Neosuchia.
} 


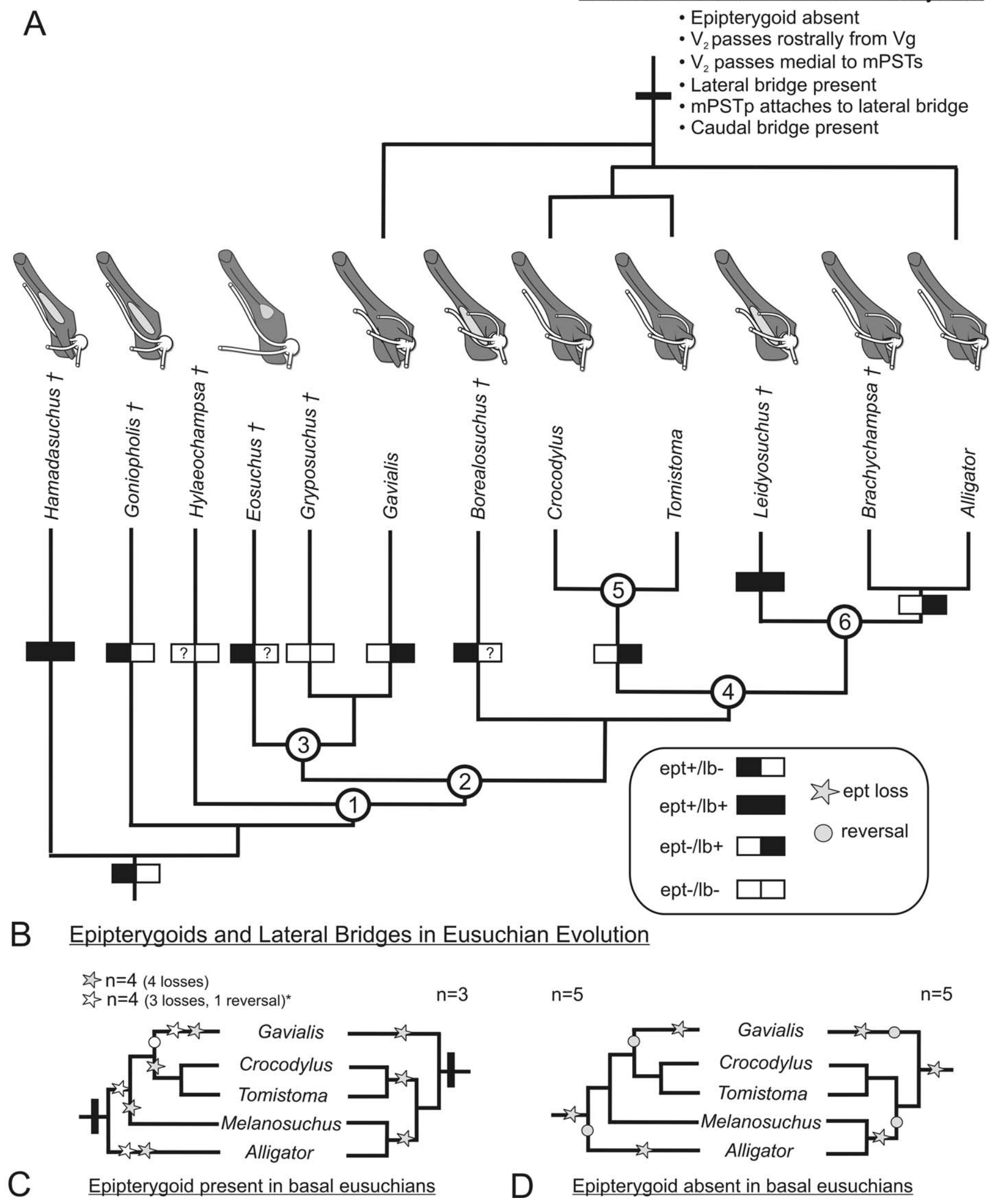


likely for the branch of vena capitis lateralis and the dorsal groove is almost certainly for the maxillary nerve, much as in Gavialis. The right laterosphenoid has a large caudal bridge that partially overhangs the dorsal trigeminal fossa. However, the flange is ventrally broken on both sides obscuring its full ventral extent. Langston and Gasparini (1997) identified a small foramen situated dorsal to the caudal bridge, from which a shallow canal rostrally exits, as being for the nerve to the constrictor dorsalis muscles, but this foramen is more likely to be for the supraorbital branch of the maxillary nerve (Fig. 12). A small, caudolaterally-oriented foramen for the caudal trigeminal artery is enveloped by the caudal bridge of the laterosphenoid and separate from the groove for the mandibular nerve.

Although the specimen is fragmentary, what is preserved provides no evidence of a laterosphenoid lateral bridge. For example, there is no evidence of a suture between a lateral bridge and the dorsal edge of the pterygoid (labeled as the basisphenoid in Langston and Gasparini [1997]). Likewise, there is no evidence for the presence of an ascending process of the palatoquadrate or any other epipterygoid-like structure. A triangular fossa between the maxillary and ophthalmic grooves indicates the attachment area of M. pseudotemporalis profundus. Therefore, it seems likely that Gryposuchus had neither an epipterygoid nor a lateral bridge.

\section{DISCUSSION}

\section{Epipterygoid Evolution}

The crocodyliform taxa described exhibit at least four different arrangements of the cavum epiptericum and orbitotemporal region, here categorized as columnar, waisted, overlapping, and isolated based on epipterygoid morphology. Among mesoeucrocodylians, Araripesuchus and Simosuchus both maintain 'nonoverlapping' epipterygoids that fail to significantly articulate across the laterosphenoid. However, these two taxa also maintain very different epipterygoid morphologies: in Simosuchus, the element appears to have been a slender, columnar rod forming the lateral wall of the cavum epiptericum, whereas the element is thin and waisted in Araripesuchus. These autapomorphic structures in these taxa confound inferring polarity with respect to other crocodyliforms. Moreover, the relationships of these taxa to other mesoeucrocodylians are problematic. Whereas Buckley et al. (2000) and Turner and Calvo (2005) grouped Simosuchus with sebecids and some notosuchians, but outside of the clade containing Araripesuchus and other 'notosuchids,' Pol and Norell (2004) found Simosuchus to be derived compared to Araripesuchus but basal to other notosuchians. Finally, although Larsson and Sues (2007) did not include Simosuchus in their phylogenetic analysis, they found Araripesuchus to be a basal metasuchian. Therefore, although these taxa offer critical data on the morphology of the orbitotemporal region, their unique morphologies and variable phylogenetic positions challenge robust interpretation.

Pelagosaurus and many longirostrine neosuchians possess 'overlapping' epipterygoids. However, like Simosuchus, the relationship of Pelagosaurus to other mesoeucrocodylian taxa is problematic. Pelagosaurus is consistently found to be basal to other thalattosuchians such as Mystriosaurus and Metriorhynchus (e.g., Clark, 1994; Turner and Calvo, 2005; Pol and Apesteguia, 2005). This clade (Pelagosaurus plus other Thalattosuchia) has been found be a basal mesoeucrocodylian clade in some analyses (Sereno et al., 2001; Tykoski et al., 2002; Turner and Calvo, 2005; Larsson and Sues, 2007). However, Pelagosaurus and thalattosuchians have also been allied with such longirostrine neosuchians as pholidosaurids and Sarcosuchus as a sister group to dyrosaurs (e.g., Pol and Norell, 2004; Pol and Apesteguia, 2005). Interestingly, Pelagosaurus and some dyrosaurs (e.g., Rhabdognathus) do share similarly shaped epipterygoid fossae and rostrolaterally directed maxillary nerves, both features that differ from Sarcosuchus and the 'waisted' morphotype (Fig. 13). However, this relationship with derived neosuchians seems incongruous given that Pelagosaurus maintains an incompletely sutured quadratebraincase junction and multiple muscles in the dorsotemporal fossa (see below), archaic features that should be primitive for all other mesoeucrocodylians, if not all crocodyliforms.

Finally, Goniopholis, Eutretauranosuchus, Eosuchus, and Leidyosuchus possess the 'isolated' epipterygoid morphotype, in which the element is decoupled from the pterygoid, sutured to the laterosphenoid, and fails to border the cavum epiptericum laterally (Figs. 11, 12, 14). When in eusuchian evolution the epipterygoid was finally eliminated remains unclear. A number of morphological patterns are shared among extant eusuchians (e.g., separate ophthalmic foramina, subfenestral pseudotemporalis superficialis muscles, apomorphic neurovascular topology, see below), but basal conditions in each extant clade suggest several independent transitional events (Fig. 14A). For example, basal gavialoid specimens appear to have an epipterygoid, but derived taxa do not, and epipterygoids also appear to be present among basal brevirostrine taxa (e.g., Leidyosuchus, Borealosuchus; Figs. 12, 14B). The most parsimonious interpretation of this pattern is that three parallel losses of the element occurred among crown-group crocodylians. Therefore, if Leidyosuchus is indeed a brevirostrine nested within Alligatoroidea (Brochu, 1997; Wu et al., 2001), then gavialoid, alligatoroid, and then also likely crocodyloid crocodylians independently eliminated the epipterygoid (Fig. 14C). The anatomy of the temporal region of most basal eusuchians admittedly still remains unclear and a valid alternative hypothesis is that basal eusuchians did not have an epipterygoid. However, this scenario would require not only a character loss at the base of the eusuchian tree but then also two reversals followed by two losses along the lines to gharials and alligators (Fig. 14D).

The evolutionary scenario is different if the characters are mapped on a crocodylian phylogeny derived from molecular data (e.g, McAlily et al., 2006) rather than morphological data. Recent molecular analyses suggests that alligators are basal relative to a clade that contains caimans, which are in turn basal to a clade that contains gharials which are then basal to a clade containing Tomistoma and crocodylids as sister taxa. If it is assumed that epipterygoids were present in basal eusuchians, two equally parsimonious scenarios are plausible. The first implies alligators, caimans, gharials, and crocodiles (including Tomistoma) independently eliminated the epipterygoid. The second scenario implies that again, alligatorids including Leidyosuchus, lost the epipterygoid, and that the last common ancestor of the Melanosuchus plus Crocodylus clade eliminated the epipterygoid, but then there was a reversal in gavialoids, which first regained an epipterygoid, and then lost it again (Fig 14C). Both of these scenarios require four steps: either four losses or three losses plus one reversal. Finally, if it again is inferred that basal eusuchians did not have an epipterygoid and characters are mapped

\footnotetext{
$\leftarrow$ FIGURE 14. Evolution of the epipterygoid and the laterosphenoid of eusuchians. A, shared features in the orbitotemporal regions of extant crocodylians; B, relevant character states mapped on eusuchian phylogeny of Brochu (1997, 1999) and Wu et al. (2001); C, epipterygoid loss mapped on two competing phylogenies of crocodylian evolution. Left tree, topology from McAliley et al. (2006); right tree, topology from Figure 14B. Epipterygoids are hypothesized to be present in stem eusuchians. D, same as C, except epipterygoids are hypothesized to be absent in stem eusuchians. Clades of interest: 1, Eusuchia; 2, Crocodylia; 3, Gavialoidea; 4, Brevirostres; 5, Crocodyloidea; 6, Alligatoroidea. The asterisk (*), white stars, and circles illustrate the second of the two equally parsimonious character transformations.
} 
onto the molecular tree, the scenario necessitates five steps: first, an initial loss at stem eusuchians, followed by reversals and then subsequent losses of the epipterygoid along both the lines to Alligator and Gavialis (Fig. 14D). Therefore, considering both molecular and morphological phylogenetic hypotheses of crocodylian taxonomy, it is most parsimonious to infer that basal eusuchians possessed epipterygoids and that the element was independently lost in gavialoids, alligatoroids, and crocodyloids.

Developmental data sheds additional light on the loss of the epipterygoid. Klembara (2004) described a large cartilaginous structure, the columella prootica, in embryonic Alligator mississippiensis that he interpreted as a partial homolog of the reptilian epipterygoid. The long, obliquely-oriented soft-tissue structure maintains a position dorsal to the trigeminal ganglion, ophthalmic nerve, and probably other cavum constituents, and passes across the ventrolateral surface of the pila antotica (i.e., the cartilaginous precursor of the laterosphenoid). This topological position is similar to that found in the epipterygoid of Goniopholis and Leidyosuchus, suggesting that a rudimentary cartilaginous anlage of the epipterygoid persists in early embryonic stages of extant crocodylians that may affect soft-tissue topology and development. Therefore, the columella prootica appears to be congruent with the ossified, adult epipterygoid in many taxa with isolated and overlapping epipterygoids.

\section{Laterosphenoid Evolution}

The elimination of the epipterygoid from the orbitotemporal region appears to have been complemented by the development the laterosphenoid lateral bridge, leading to the formation of a new secondary bony wall of the cavum epiptericum. The mechanical factors driving the need to enclose the soft tissues in bone are unclear (e.g., extra muscle attachment, protection), and the structure is ontogenetically variable (extant crocodylians do not hatch with a lateral bridge). However, the character transitions still appear linked. The first clear example of a complete laterosphenoid lateral bridge among neosuchians in found in Hamadasuchus, but not again until among basal taxa of Brevirostres, including the alligatoroid Brachychampsa montana (UCMP 133901), the crocodyloid Brachyuranochampsa sp. (AMNH 16609), and some fossil gavialoids (e.g., Eogavialis africanum, AMNH 5607). However, Hylaeochampsa, goniopholidids, the gavialoids Gryposuchus and Eosuchus minor (USNM 15726), do not have lateral bridges, and they are only partially formed in Leidyosuchus and an undescribed longirostrine Cretaceous Madagascar taxon (UA 98591). Nonetheless, the lateral bridge co-occurs with the epipterygoid in Hamadasuchus (ROM 54511) and Leidyosuchus (CMN 8942, TMP 83.25.03) confirming that the two elements are non-homologous structures with convergent topological positions. Therefore, given the available data, it appears that the lateral bridges of Hamadasuchus, gavialids, and brevirostrines may be independent, convergent extensions of the laterosphenoid (i.e., non-homologous lateral bridges; Fig. 14B).

The caudal laterosphenoid bridge appeared in mesoeucrocodylians prior to the lateral bridge, although it appears to be highly variable. This caudally directed bony extension of the laterosphenoid forms the ventral wall of the canal for the supraorbital nerve in Araripesuchus, Gryposuchus, and extant taxa (Figs. 3, 4, 7, 11). Sebecus icaeorhinus (AMNH 39734) has a distinct groove for the supraorbital nerve on the ventral surface of the dorsal rim of the trigeminal fossa, but no clear evidence of a caudal bridge. The caudal laterosphenoid bridge is small among many extant taxa (e.g., Alligator mississippiensis) where it only encloses the supraorbital nerve. Alternatively, as in Crocodylus acutus, the caudal bridge may be greatly enlarged, overhanging the groove for the maxillary nerve, or as in Gryposuchus, the element may envelop the caudal trigeminal artery. Nonetheless, the caudal bridge of extant taxa does not typically extend caudally to overlap the proo- tic or the quadrate as observed in Gryposuchus (Fig. 11). This suggests the caudal bridge may be highly variable and homoplastic among mesoeucrocodylians.

\section{Soft-tissue Evolution}

The elimination of the epipterygoid as the lateral wall of the cavum epiptericum modified the topological relationships between the maxillary nerve and the adductor musculature (Figs. 4, 5). In reptiles the maxillary nerve plesiomorphically travels laterally from the maxillomandibular foramen, and then courses rostrally from behind the epipterygoid and passes between Mm. pseudotemporalis superficialis and $\mathrm{M}$. adductor mandibulae externus profundus (Luther, 1914; Lubosch, 1914; Lakjer, 1926; Edgeworth, 1935; Holliday and Witmer, 2007; Fig. 1). Because the nerve does not contact any bony elements, it does not leave any osteological correlates indicative of its course. Most non-crocodyliform suchians exhibit this morphology. In mesoeucrocodylian taxa with epipterygoids that span the cavum epiptericum (e.g., Sarcosuchus), the maxillary nerves initially exit the fossa caudolaterally and then likely curve rostrally at some point within the adductor chamber, skirting soft tissues directly overlying the epipterygoid (Fig. 15). Others (e.g., Pelagosaurus, Rhabdognathus) exhibit tapering rostrally-oriented maxillary nerve grooves on the caudolateral surface of the laterosphenoid (Fig. 15). However, the directionality and short length of the grooves still indicate a strong lateral deviation of the nerves around structures immediately rostromedial to them such as the epipterygoid and its attaching musculature. This morphology changed in Goniopholis and Eutretauranosuchus, where the course of the maxillary nerve appears to have become directed rostrally, but, because of the lack of a cavum epiptericum wall (i.e., overlapping epipterygoid or lateral bridge), there are no relevant osteological correlates. Finally, in Crocodylia (e.g., Gryposuchus, Leidyosuchus, Alligator, Crocodylus, Gavialis), the maxillary nerve exits the maxillomandibular foramen rostrally, leaving marked osteological correlates on the laterosphenoid, and passes medial to M. pseudotemporalis superficialis (Figs. 3, 4, 14).

The elimination of the epipterygoid also accompanied changes in the position of M. pseudotemporalis superficialis. In basal suchians, most birds, and squamates, M. pseudotemporalis superficialis occupies the rostral portion of the dorsotemporal fossa (here termed an 'intrafenestral' position), where it shares space with bellies of the $\mathrm{Mm}$. adductor mandibulae externus group (e.g., M. adductor mandibulae externus profundus). On the other hand, M. pseudotemporalis superficialis (Holliday and Witmer, 2007; = M. adductor mandibulae externus profundus pars rostralis [Schumacher, 1973; Busbey, 1989]) attaches to the caudolateral surface of the laterosphenoid outside of the dorsotemporal fossa in extant crocodylians (Fig. 3), here termed a subfenestral position.

During mesoeucrocodylian evolution, M. pseudotemporalis superficialis migrated to a subfenestral position on the caudal surface of the laterosphenoid, near the position that the epipterygoid once occupied. Most non-neosuchian crocodylomorphs including sphenosuchians, protosuchians, Pelagosaurus, and thalattosuchians possess osteological correlates indicative of several muscles that filled the dorsotemporal fossa. On the other hand, it is clear that only M. adductor mandibulae externus profundus occupied the dorsotemporal fossa in other mesoeucrocodylians (e.g., Araripesuchus, Simosuchus) and most neosuchians including Sarcosuchus, Rhabdognathus, Hamadasuchus, Goniopholis, and Leidyosuchus, which suggests that this transition occurred early in mesoeucrocodylian evolution. Given that there is no evidence of where M. pseudotemporalis profundus attached, particularly in Goniopholis and Eutretauranosuchus (Fig. 10), and the muscle attaches ventral to the trigeminal ganglion and the maxillary nerve in extant Crocodylia (Fig. 3), both $\mathrm{Mm}$. 

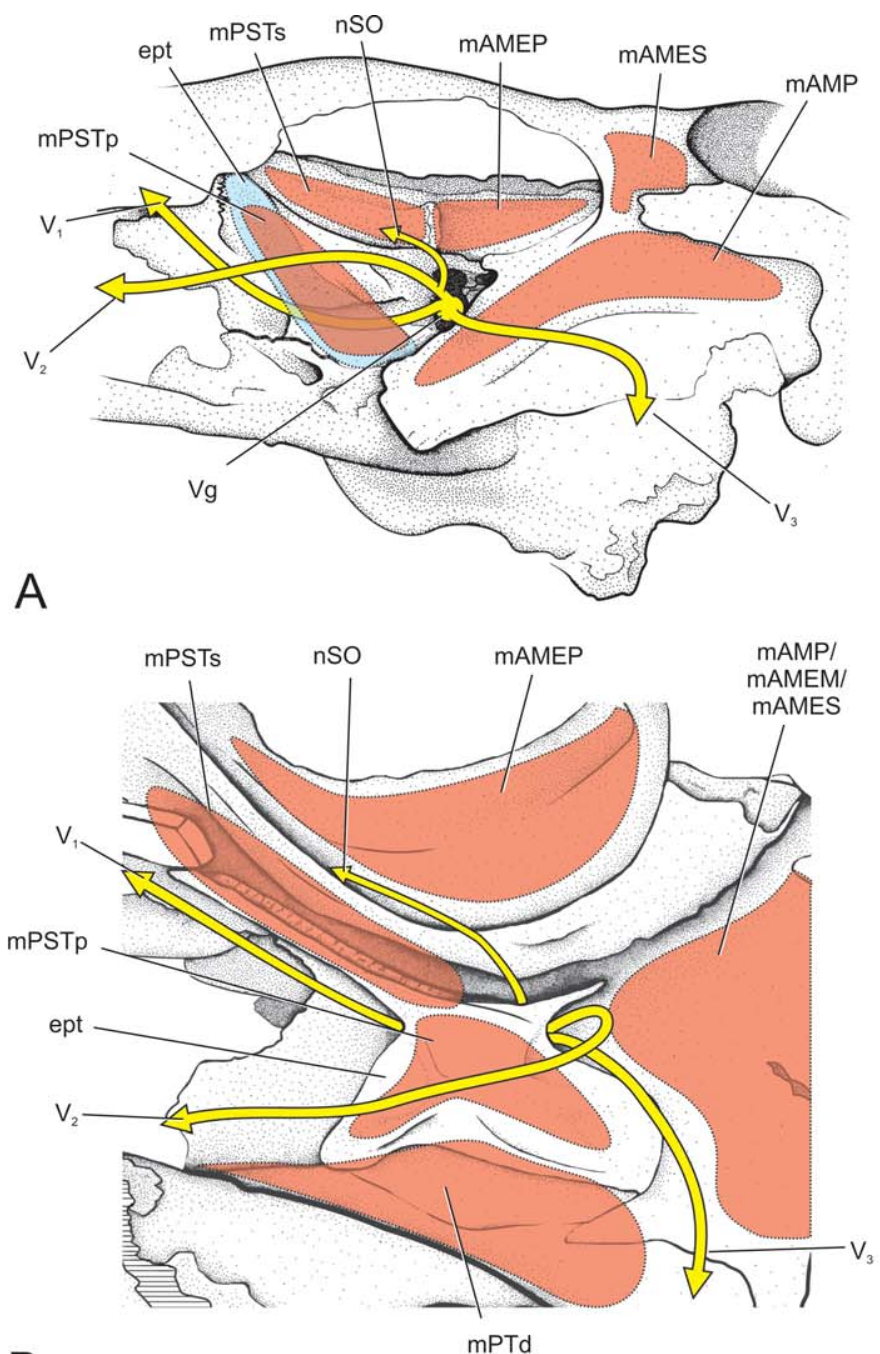

B

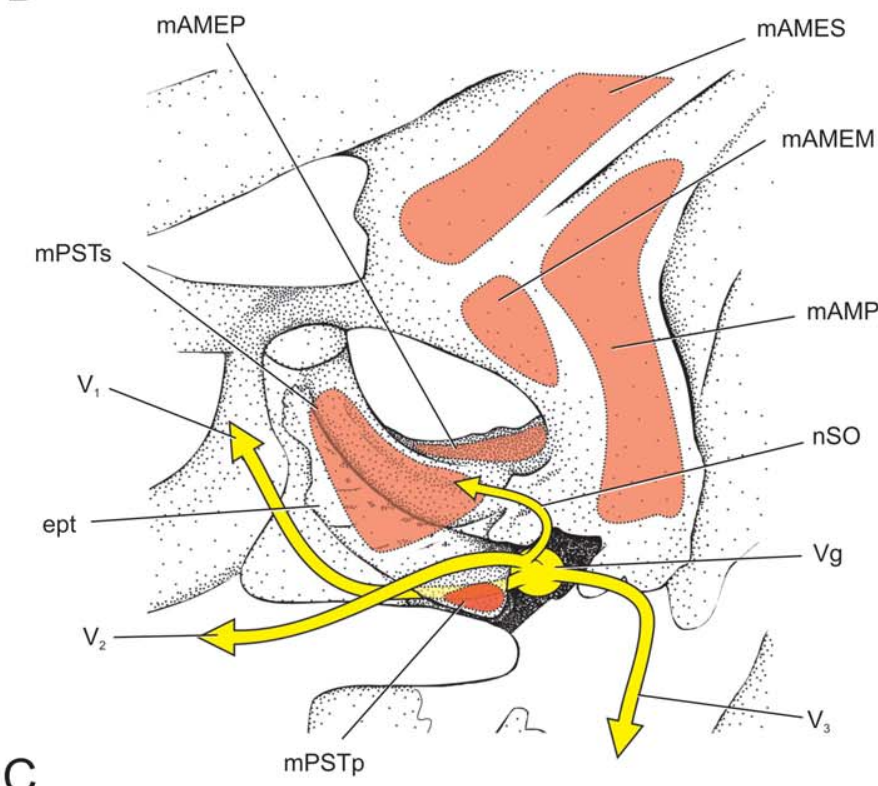

FIGURE 15. Reconstructed jaw muscle attachments and trigeminal nerve branches in mesoeucrocodylians that exhibit the focal epipterygoid morphotypes discussed in analysis. Illustrations are from previous figures. A, Pelagosaurus (with epipterygoid reconstructed); B, Sarcosuchus; C, Leidyosuchus. pseudotemporalis profundus and superficialis must have uncoupled from their plesiomorphic bony attachments, the epipterygoid and dorsotemporal fossa, respectively (Fig. 1), and shifted ventrally onto the lateral bridge and postorbital process of the laterosphenoid during mesoeucrocodylian evolution. This transformational hypothesis also suggests that M. pseudotemporalis superficialis also may have migrated onto the epipterygoid (e.g., Fig. 15C), thus attaching in the region where it is currently found in extant taxa (Lakjer, 1926; Schumacher, 1973; Holliday and Witmer, 2007). These findings indicate that longirostrine thalattosuchians possessed dorsotemporal fossae with minimally two muscles (Mm. pseudotemporalis superficialis and adductor mandibulae externus profundus) whereas longirostrine neosuchians possessed fossae with only one temporal muscle (M. adductor mandibulae externus profundus; Fig. 13). Whether or not these anatomical differences had any functional significance remains to be determined because simple muscle hypertrophy, like that found in Gavialis, may compensate for the lack of a multi-temporal-muscle system.

To conclude, this analysis indicates that the epipterygoid was a consistent feature of the suchian adductor chamber and persisted through the diversification of eusuchian crocodyliforms (Figs. 12, 14). These data demonstrate the transition of the epipterygoid from: (1) serving as an anatomical boundary of the cavum epiptericum and bony strut linking the palate to the braincase in basal crocodylomorphs (Fig. 1); (2) to suturing to the laterosphenoid and bridging the cavum epiptericum in most non-eusuchian mesoeucrocodylians; (3) to uncoupling from the pterygoid and exposing the cavum epiptericum laterally in some neosuchians and basal eusuchians (Fig. 14); (4) to being eliminated from the adult head skeleton in extant forms (Figs. 1, 3, 4). Non-homologous laterosphenoid lateral bridges appear to have evolved in parallel with the elimination of the epipterygoid as the lateral wall of the cavum epiptericum (Fig. 14). Changes in the muscular topology of the dorsotemporal fossa also appear to have accompanied these changes in the orbitotemporal region (Fig. 15). The elimination of the epipterygoid is potentially an apomorphic, homoplastic feature of individual clades of Eusuchia and thus a relatively recent morphological transformation along the suchian lineage.

\section{ACKNOWLEDGMENTS}

This study greatly benefited from discussions with Christopher Brochu, David Dufeau, Tobin Hieronymus, Josef Klembara, Diego Pol, Olivier Rieppel, Alan Turner, and many others. The comments of Hans Larsson, Sean Modesto, and an anonymous reviewer greatly improved the paper. Gregory Buckley, Christopher Brochu, Sterling Nesbitt, and Paul Sereno granted access to unpublished specimens. Thanks to Stephanie Pierce, Michael Benton, Oscar Alcober, and Tim Rowe for access to CT data. We thank Mark Norell (AMNH), Paul Sereno (UC), William Simpson, Gregory Buckley, and Alan Resetar (FMNH), Kevin Padian and Pat Holroyd (UCMP), Angela Milner (BMNH), and Oscar Alcober (PVSJ) for access to specimens. Parts of this study were funded by Joan C. Edwards School of Medicine, Marshall University, UCMP Samuel P. Welles fund, The Jurassic Foundation, Ohio University Graduate Student Senate Award, Ohio University Student Enhancement Award (to $\mathrm{CMH}$ ), NSF IBN-0407735 (to LMW and CMH), and NSF IOB0343744 (to LMW).

\section{LITERATURE CITED}

Alcober, O. 2000. Redescription of the skull of Saurosuchus galilei (Archosauria: Rauisuchidae). Journal of Vertebrate Paleontology 20:302-316.

Bellairs, A. d'A., and A. M. Kamal. 1981. The chondrocranium and the development of the skull in recent reptiles; pp. 3-262 in C. Gans, 
(ed.), Biology of the Reptilia. Volume 11, Morphology F. Academic Press, New York.

Brochu, C. A. 1997. Fossils, morphology, divergence timing, and the phylogenetic relationships of Gavialis. Systematic Biology 46:479-522.

Brochu, C. A. 1999. Phylogenetics, taxonomy, and historical biogeography of Alligatoroidea. Journal of Vertebrate Paleontology 19:9-100.

Brochu, C. A. 2001. Progress and future directions in archosaur phylogenetics. Journal of Paleontology 75:1185-1201.

Brochu, C. A. 2004. A new Late Cretaceous gavialoid crocodylian from eastern North America and the phylogenetic relationships of thoracosaurs. Journal of Vertebrate Paleontology 24:610-633.

Brochu, C. A. 2007. Morphology, relationships, and biogeographical significance of an extinct horned crocodile (Crocodylia, Crocodylidae) from the Quaternary of Madagascar. Zoological Journal of Linnean Society 150:835-863.

Brochu, C. A., and A. D. Rincón. 2004. A gavialoid crocodylian from the Lower Miocene of Venezuela. Special Papers in Paleontology 71:61-79.

Brochu, C. A., M. L. Bouaré, S. Sissoko, E. M. Robers, and M. A. O'Leary. 2002. A dyrosaurid crocodyliform braincase from Mali. Journal of Paleontology 76:1060-1071.

Buckley, G. A., C. A. Brochu, D. W. Krause, and D. Pol. 2000. A pugnosed crocodyliform from the Late Cretaceous of Madagascar. Nature 405:941-944.

Busbey, A. B. III 1989. Form and function of the feeding apparatus of Alligator mississippiensis. Journal of Morphology 202:99-127.

Busbey, A. B. III 1995. The structural consequences of skull flattening in crocodilians; pp. 173-193 in J. J. Thomason, (ed.), Functional Morphology in Vertebrate Paleontology. Cambridge University Press, New York.

Clark, J. M. 1994. Patterns of evolution in Mesozoic Crocodyliformes; pp. 84-97 in N. Fraser and H.-D. Sues (eds.), In the Shadow of the Dinosaurs: Early Mesozoic Tetrapods. Cambridge University Press, Massachusetts.

Clark, J. M., J. Welman, J. A. Gauthier, and J. M. Parrish. 1993. The laterosphenoid bone of early archosauriforms. Journal of Vertebrate Paleontology 13:48-57.

de Beer, G. R. 1937. The Development of the Vertebrate Skull. Clarendon Press, Oxford, 550 pp.

Edgeworth, F. H. 1935. The Cranial Muscles of Vertebrates. Cambridge University Press, Cambridge, $493 \mathrm{pp}$

Endo, H., R. Aoki, H. Taru, J. Kimura, M. Sasaki, M. Yamamoto, K. Arishima, and Y. Hayashi. 2002. Comparative functional morphology of the masticatory apparatus in the long-snouted crocodiles. Anatomy, Histology, and Embryology 31:206-213.

Eudes-Deslongchamps, J. A. 1863. Memoires surles teleosauriens de l'Epoque Jurassique du Departement du Calvados. Memoire Societe Linne Normandie 12, 135 pp.

Gardiner, B. G. 1982. Tetrapod classification. Zoological Journal of the Linnean Society 75:207-232.

Gaupp, E. 1902. Über die Ala temporalis des Säugerschädels und die Region orbitalis einiger anderer Wirbeltierschädel. Anatomische Hefte 1. Abt 19:155-230.

Gow, C. E. 2000. The skull of Protosuchus haughtoni, an Early Jurassic crocodyliform from southern Africa. Journal of Vertebrate Paleontology 20:49-56.

Haas, G. 1973. Muscles of the jaws and associated structures in the Rhynchocephalia and Squamata; pp. 285-490 in C. Gans and T. S. Parsons (eds.), Biology of the Reptilia, Volume 4. Academic Press, New York.

Hofer, H. 1950. Zur Morphologie der Kiefermuskulatur der Vögel. Zoologische Jahrbucher: Abteilung für Anatomie und Ontogenie der Tiere 70:427-556.

Holliday, C. M. 2006. Evolution and function of the jaw musculature and adductor chamber of archosaurs (crocodilians, dinosaurs, and birds). Ph.D. dissertation, Ohio University, Athens, Ohio, 325 pp.

Holliday, C. M., and L. M. Witmer. 2007. Archosaur adductor chamber evolution: integration of musculoskeletal and topological criteria in jaw muscle homology. Journal of Morphology 268:457-484.

Hopson, J. A. 1979. Paleoneurology; pp. 39-146 in C. Gans, (ed.), Biology of the Reptilia, Volume 9. Academic Press, London.

Hopson, J. A., and G. W. Rougier. 1993. Braincase structure in the oldest known skull of a therian mammal: implications for mammalian systematics and cranial evolution. American Journal of Science 293-A:268-299.
Hua, S., and S. Jouve. 2004. A primitive marine gavialoid from the Paleocene of Morocco. Journal of Vertebrate Paleontology 24:341-350.

Iordansky, N. N. 1964. The jaw muscles of the crocodiles and some relating structures of the crocodilian skull. Anatomischer Anzeiger 115:256-280.

Iordansky, N. N. 1973. The skull of the Crocodilia; pp. 201-262 in C. Gans and T. S. Parsons (eds.), Biology of the Reptilia, Volume 4. Academic Press, New York.

Jouve, S. 2005. A new description of Dyrosaurus phosphaticus (Thomas, 1893) (Mesoeucrocodylia: Dyrosauridae) from the Lower Eocene of North Africa. Canadian Journal of Earth Sciences 42:323-337.

Killian, G. 1890. Die Ohrmuskeln des Krokodiles nebst vorläufigen Bemerkungen über die Homologie des Musculus stapedius und des Stapes. Jenaische Zeitschrift für Naturwissenschaft 24:632-656.

Klembara, J. 2004. Ontogeny of the palatoquadrate and adjacent lateral cranial wall of the endocranium in prehatching Alligator mississippiensis (Archosauria: Crocodylia). Journal of Morphology 263:644-658.

Klembara, J., and J. Welman. 2007. The anatomy of the pterygoquadrate of the Lower Triassic Proterosuchus fergusi (Reptilia, Archosauromorpha) from South Africa. Journal of Morphology 268:1093.

Lakjer, T. 1926. Die Trigeminus-Versorgte Kaumuskulature der Sauropsiden. Auf kosten der Carlsbergstiftung, Kopenhagen, 154 pp.

Langston, W. Jr. 1973. The crocodilian skull in historical perspective; pp. 263-285 in C. Gans and T. S. Parsons (eds.), Biology of the Reptilia, Volume 4. Academic Press, New York.

Langston, W. Jr, and Z. Gasparini. 1997. Crocodilians, Gryposuchus, and the South American gavials; pp. $113-154$ in R. F. Kay, R. H. Madden, R. L. Cifelli, and J. J. Flynn (eds.), Vertebrate Paleontology in the Neotropics: the Miocene fauna of La Venta, Colombia. Smithsonian Institution Press, Washington.

Larsson, H. C. E., and H-D. Sues. 2007. Cranial osteology and phylogenetic relationships of Hamadasuchus rebouli (Crocodyliformes: Mesoeucrocodylia) from the Cretaceous of Morocco. Zoological Journal of the Linnean Society 149:533-567.

Lubosch, W. 1914. Vergleichende Anatomie der Kaumuskulatur der Wirbeltiere, in fünf Teilen: 1. Die Kaumuskulatur der Amphibien. Jen Z Naturwiss 53:51-188.

Luther, A. 1914. Über die vom N. trigeminus versorgte Muskulatur der Amphibien, mit einem vergleichenden Ausblick über den Adductor mandibulae der Gnathostomen, und einem Beitrag zum Verständnis der Organisation der Anerunlarven. Acta Societatis Scientiae Fennicae 44:1-151.

McAliley, L. R., R. E. Willis, D. A. Ray, P. S. White, C. A. Brochu, and L. D. Densmore. III 2006. Are crocodiles really monophyleticEvidence for subdivisions from sequence and morphological data. Molecular Phylogenetics and Evolution 39:16-32.

Modesto, S. P., and J. S. Anderson. 2004. The phylogenetic definition of Reptilia. Systematic Biology 53:815-821.

Norell, M. A., and J. M. Clark. 1991. A reanalysis of Bernissartia fagesii, with comments on its phylogenetic position and its bearing on the origin and diagnosis of the Eusuchia. Bulletin Institut National de Sciences Naturelles, Belgique 60:115-128.

Oelrich, T. M. 1956. The anatomy of the head of Ctenosaura pectinata (Iguanidae). Miscellaneous Publications, Museum of Zoology, University of Michigan, Ann Arbor, 94 pp.

Ortega, F., Z. Gasparini, A. D. Buscalioni, and J. O. Calvo. 2000. A new species of Araripesuchus (Crocodylomorpha, Mesoeucrocodylia) from the Lower Cretaceous of Patagonia (Argentina). Journal of Vertebrate Paleontology 20:57-76.

Patterson, C. 1982. Morphological characters and homology; pp. 21-74 in K. A. Joysey and A. E. Friday (eds.), Problems of Phylogenetic Reconstruction. Academic Press, London and New York.

Pierce, S. E., and M. J. Benton. 2006. Pelagosaurus typus Bronn, 1841 (Mesoeucrocodylia: Thalattosuchia) from the Upper Lias (Toarcian, Lower Jurassic) of Somerset, England. Journal of Vertebrate Paleontology 26:621-635.

Pol, D., and M. A. Norell. 2004. A new crocodyliform from Zos Canyon, Mongolia. American Museum Novitates 3445:1-36.

Pol, D., and S. Apesteguia. 2005. New Araripesuchus remains from the early Late Cretaceous (Cenomanian-Turonian) of Patagonia. American Museum Novitates 3490:1-38.

Rieppel, O. 1993. Patterns of diversity in the reptilian skull; pp. 344-390 in J. Hanken and B. K. Hall (eds.), The Skull, Volume 2: Patterns of 
Structural and Systematic Diversity. University of Chicago Press, Chicago.

Schumacher, G. H. 1973. The head muscles and hyolaryngeal skeleton of turtles and crocodilians; pp. 101-200 in C. Gans and T. S. Parsons (eds.), Biology of the Reptilia, Volume 4. Academic Press, New York.

Sedlmayr, J. C. 2002. Anatomy, evolution, and functional significance of cephalic vasculature in Archosauria. Ph.D. dissertation. Ohio University, Athens, Ohio, $398 \mathrm{pp}$.

Sereno, P. C, H. C. E. Larsson, C. A. Sidor, and B. Gado. 2001. The giant crocodyliform Sarcosuchus from the Cretaceous of Africa. Science 294:1516-1519.

Sereno, P. C., C. A. Sidor, H. C. E. Larsson, and B. Gado. 2003. A new notosuchian from the Early Cretaceous of Niger. Journal of Vertebrate Paleontology 23:477-482.

Sereno, P. C., J. A. Wilson, and J. L. Conrad. 2004. New dinosaurs link southern landmasses in the Mid-Cretaceous. Proceedings of the Royal Society B 271:1325-1330.

Turner, A. H. 2004. Crocodyliform biogeography during the Cretaceous: evidence of Gondwanan vicariance from biogeographical analysis. Proceedings of the Royal Society B 271:2003-2009.

Turner, A. H. 2006. Osteology and phyologeny of a new species of Araripesuchus (Crocodyliformes: Mesoeucrocodylia) from the Late Cretaceous of Madagascar. Historical Biology 18:255-269.

Turner, A. H., and J. O. Calvo. 2005. A new sebecosuchian crocodyliform from the Late Cretaceous of Patagonia. Journal of Vertebrate Paleontology 25:87-98.
Tykoski, R. S., T. B. Rowe, R. A. Ketcham, and M. W. Colbert. 2002. Calsoyasuchus valliceps, a new crocodyliform from the Early Jurassic Kayenta Formation of Arizona. Journal of Vertebrate Paleontology 22:593-611.

Vanden Berge, J. C., and G. A. Zweers. 1993. Myologia; pp. 189-250 in J. J. Baumel (ed.), Handbook of Avian Anatomy: Nomina Anatomica Avium, 2nd edition. Nuttall Ornithological Society, Cambridge, Massachusetts.

Walker, A. D. 1990. A reevaluation of Sphenosuchus acutus Haughton, a crocodylomorph reptile from the Elliot Formation of the Triassic or early Jurassic of South Africa. Philosophical Transactions of the Royal Society of London B 330:1-120.

Witmer, L. M. 1995. Homology of facial structures in extant archosaurs (birds and crocodilians), with special reference to paranasal pneumaticity and nasal conchae. Journal of Morphology 225:269-327.

Witmer, L. M., R. C. Ridgely, D. L. Dufeau, and M. C. Semones. 2008. Using CT to peer into the past: 3D visualization of the brain and ear regions of birds, crocodiles, and nonavian dinosaurs; pp. 67-87 in H. Endo and R. Frey (eds.), Anatomical Imaging: Towards a New Morphology. Springer-Verlag, Tokyo.

Wu, X.-C., D. B. Brinkman, and R. C. Fox. 2001. A new crocodylian (Archosauria) from the Paleocene of the Red Deer River Valley, southern Alberta. Canadian Journal of Earth Sciences 38: 1689-1704.

Submitted October 27, 2008; accepted October 29, 2008. 